\title{
The Lattice Spacing Variability of Intrinsic Float-Zone Silicon
}

\author{
Ernest G. Kessler ${ }^{1}$, Csilla I. Szabo ${ }^{1,2}$, James P. Cline ${ }^{1}$, Albert Henins ${ }^{1}$, Lawrence T. Hudson ${ }^{1}$, Marcus \\ H. Mendenhall ${ }^{1}$, and Mark D. Vaudin ${ }^{1}$ \\ ${ }^{1}$ National Institute of Standards and Technology, \\ Gaithersburg, MD 20899, USA \\ ${ }^{2}$ Theiss Research, \\ La Jolla, CA 92037, USA
}

ernest.kessler@nist.gov csilla.szabo-foster@nist.gov james.cline@nist.gov

albert.henins@nist.gov lawrence.hudson@nist.gov marcus.mendenhall@nist.gov mark.vaudin@nist.gov

Precision lattice spacing comparison measurements at the National Institute of Standards and Technology (NIST) provide traceability of X-ray wavelength and powder diffraction standards to the international system of units (SI). Here, we both summarize and document key measurements from the last two decades on six lots of intrinsic float-zone silicon, including unpublished results and recent internal-consistency checks. The comparison measurements link the unknown lattice spacing of a test crystal to a standard crystal for which the lattice spacing has been accurately determined by X-ray/optical interferometry in units traceable to the definition of the meter. The crystal that serves as the standard in all the comparisons is WASO 04, for which the lattice spacing is known with a relative uncertainty of $5 \times 10^{-9}$. Individual lattice spacing comparison results have typical uncertainties of $1 \times 10^{-8}$; taking material variability into account, measurements yield relative uncertainties for the test materials of a few tens of nanometers. It is observed that in the case of nearly perfect modern intrinsic float-zone silicon, the variability of the lattice spacing is sufficiently small that for most diffraction applications, a recommended reference value may be used.

Key words: lattice parameter; lattice spacing difference; silicon crystal; Standard Reference Material; X-ray diffraction; X-ray spectrometer.

Accepted: April 10, 2017

Published: May 11, 2017

https://doi.org/10.6028/jres.122.024

\section{Introduction}

In the early 1990s, a crystal diffraction instrument was developed at the National Institute of Standards and Technology (NIST) for the accurate comparison of crystal lattice spacing values. The original instrument, commonly called the NIST lattice comparator or, colloquially, the "delta-d" machine, is described in detail in Ref. [1]. Through the last 25 years, this instrument has been operational in four different locations at the NIST Gaithersburg, MD laboratory (two locations in the basement of Building 221, the Advanced Measurement Laboratory [AML], and the first floor of Building 223) and the responsibility of two NIST laboratories (Physical Measurement Laboratory [PML] and Materials Measurement Laboratory [MML]). From 1998 to 2011, the NIST lattice comparator played an important role in the International Avogadro Project by measuring lattice parameter variations in highly perfect isotopically natural silicon material and highly enriched ${ }^{28} \mathrm{Si}$ material [2-4]. More recently, the scope of 
possible lattice comparator measurements was expanded to include the measurement of the curvature of coated silicon wafers [5]. To accommodate this new effort, as well as to improve the original capacity of the machine, the sample mounting, alignment, and transport devices were significantly upgraded.

Lattice comparison measurements are directed to two main outcomes: (1) the determination of the absolute lattice spacing of nearly perfect crystals used for X-ray and gamma-ray wavelength measurements, and (2) the determination of the lattice spacing variability within a large volume of silicon. Diffraction instruments at NIST [6, 7], the Institut Laue-Langevin (ILL) in Grenoble, France [8], and the Laboratoire Kastler Brossel (LKB) in Paris, France [9] use crystals for which the lattice spacings were determined through comparison measurements. The lattice spacing variability of silicon used to produce Standard Reference Materials (SRMs) [10-14] and of the large boules of silicon associated with the International Avogadro Project $[2,4]$ was verified through lattice comparisons as well. Although some of the lattice comparator measurements have been included in wavelength and Avogadro-constant publications, many measurements have appeared only in SRM Certificates of Analysis and in internal reports. In addition, over the years, the absolute lattice spacings of the standard crystals used in the lattice comparator measurements have been updated as the result of improved absolute lattice spacing measurements. In this paper, we provide absolute lattice spacing values for silicon material measured on the NIST lattice comparator that have never been published in an archival journal, and we update previously published absolute lattice spacing values. The silicon feedstock used for fabrication of the diffraction crystals and certification of the SRMs came to NIST in six separate lots. This report includes measurements on (1) silicon used in the Vacuum Double Crystal Spectrometer (VDCS) of the PML at NIST and the gamma-ray instruments at the ILL, (2) a second silicon sample used in the gamma-ray instruments, (3) silicon used in the vacuum double crystal spectrometer at LKB (known by the local acronym DCS), (4) silicon used in the Parallel Beam Diffractometer (PBD) of the MML at NIST and to produce SRMs 640d, 640e, and 640f, (5) a second silicon sample also used to produce SRMs 640d, 640e, and 640f, and (6) silicon used to produce SRM 640c. Taken together, these measurements allow the characterization of the variability of commercial, nearly perfect float-zone silicon, both from boule to boule and within a given ingot. This in turn informs the uncertainty analysis. Finally, we tabulated average absolute lattice spacings for key standard reference crystals and compared the values to the "Committee on Data for Science and Technology (CODATA) Recommended Values of the Fundamental Physical Constants: 2014” value for natural silicon. [15]

In a 1978 publication describing a Bragg-spacing comparator, the authors included a survey of lattice parameter variations in silicon crystals available at that time from different suppliers [16]. The range of relative lattice parameter differences for 19 samples of float-zone silicon was approximately $1 \times 10^{-6}$. The range of the relative lattice parameter differences for the six samples measured in this paper is approximately $4 \times 10^{-8}$. This reduction in lattice parameter variability in float-zone silicon is primarily associated with the reduction of carbon and oxygen impurity concentrations in the silicon crystals used for diffraction today.

\section{Lattice Comparison Measurement Procedure}

Although the principle, the apparatus, the crystals, and the measurement procedure of the lattice comparator were fully described in Ref. [1], this abbreviated section provides background for the measurements that are described later herein. The lattice comparator measures the difference in Bragg angle, $\Delta \theta$, between a standard crystal and an unknown crystal. The relative lattice spacing difference,

$$
\frac{\left(d_{\text {unknown }}-d_{\text {standard }}\right)}{d_{\text {standard }}},
$$

follows directly from $\Delta \theta$ using Bragg's law. It is common practice to report the difference between the lattice spacings of an unknown and standard crystal as a relative lattice spacing difference which is a dimensionless quantity. Similarly, the uncertainty of a relative lattice spacing difference is a dimensionless quantity.

The standard and the unknown crystals are mounted on a translation table, as shown on Fig. 1, and are sequentially placed in the second crystal position of the two-crystal transmission diffraction instrument. Because the diffracted $\mathrm{X}$-rays pass through the crystals, an average lattice spacing distribution along the $\mathrm{X}$ - 
ray path is sensed. More localized lattice spacing variations have been measured using a reflective geometry lattice comparator coupled to a synchrotron radiation source [17].

The traceability of the standard is discussed in Sec. 3.1. The lattice spacings of the standard and the unknown are compared to the lattice spacing of the first long crystal. Then, the lattice spacing of the first long crystal is eliminated by subtraction to obtain the relative lattice spacing difference between the standard and the unknown crystals.

The design of the NIST lattice comparator closely follows the symmetric Laue case geometry suggested by Hart [18]. However, the NIST lattice comparator, schematically shown in Fig. 1, includes several features that contribute to accurate comparison of lattice parameters. The lattice comparator has two sources, two detectors, and shutters that allow nearly simultaneous recording of profiles for $\mathrm{x}$ rays traversing the dashed (source S1 to detector D2) and solid (source S2 to detector D1) paths. Since the two profiles are essentially recorded at the same time, drifts related to temperature and instrument stability are minimized. The first and second crystal thicknesses are chosen and matched so that the profiles exhibit pronounced Pendellösung oscillations that aid in the determination of the angular separation between the two profiles. For the NIST lattice comparator, the target crystal thickness is $0.455 \mathrm{~mm}$. The standard and unknown crystals reside on a transport device that allows automatic interchange of the samples. In a typical data run lasting 14 to $20 \mathrm{~h}, 16$ to 24 sets of profiles are recorded, equally divided between the standard and the unknown crystals.

The typical uncertainty of a single data run is 5 to $10 \times 10^{-9}$, which includes statistical components ( 3 to $\left.9 \times 10^{-9}\right)$ and three systematic components: crystal temperature $\left(3 \times 10^{-9}\right)$; crystal alignment $\left(1 \times 10^{-9}\right)$; and location of X-ray paths and crystals $\left(3 \times 10^{-9}\right)$. A lattice comparison always includes multiple data runs (usually five or more), each of which contains approximately the same number of profiles. The lattice comparison uncertainties given in this paper are the standard deviation (coverage factor $k=1$ ) obtained from the multiple data runs and are usually in the 5 to $20 \times 10^{-9}$ range.

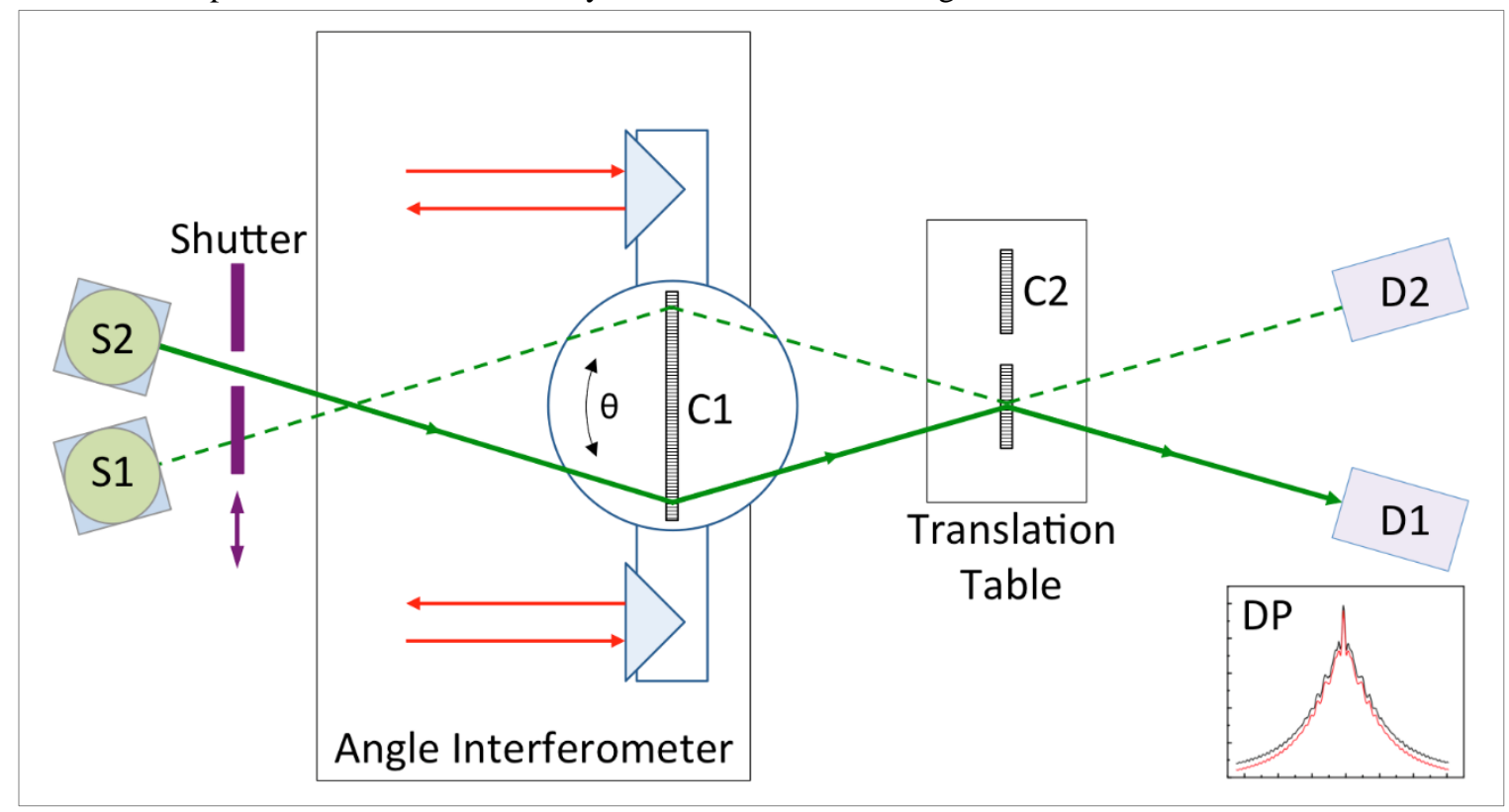

Fig. 1. Sketch of the lattice comparator instrument, where S1 and S2 are X-ray sources; C1 and C2 are crystals; D1 and D2 are detectors; and DP is the diffraction profile.

As measurements presented in this paper confirm, the Si feed stock, from which diffraction crystals and lattice comparator crystals are cut, exhibits relative lattice spacing variability in the neighborhood of 25 $\times 10^{-9}$. Thus, it is appropriate to include an additional variability uncertainty term in the determination of the lattice parameter of a Si boule and a particular diffraction crystal. Furthermore, the measurements in Sec. 8 focus on measuring the variability of $30 \mathrm{~kg}$ to $40 \mathrm{~kg}$ of Si material. For SRMs, the preferred 
uncertainty is two standard deviations ( $k=2,95 \%$ confidence limits), and the lattice parameters determined in this section honor this preference.

\section{Lattice Comparator Crystals}

This study involved samples of high-quality natural silicon material that fit into three categories: standard crystals for which the lattice spacing has been accurately measured, transfer crystals that provide a link to the standard crystals, and silicon material for which the lattice spacing is being determined. The standard and transfer crystal materials have been the subject of many publications over 40 years, and, unfortunately, the identification of the materials has not always been consistent. All of the standard and transfer silicon materials used in this paper were also included in the 2014 CODATA recommended values of the fundamental physical constants [15]. The names of the stock materials, including the simplified forms, were taken from the CODATA publication.

\subsection{Standard Crystals}

The desired outcome of most lattice comparison measurements is the lattice spacing of the unknown crystal with the smallest possible uncertainty. Thus, the lattice spacing of the standard crystal must be known with high accuracy. The most accurate measurements of the lattice spacing of silicon are made with combined X-ray/optical interferometers, where the optical path is connected to the definition of the meter in the International System of Units (SI). A silicon sample that is adjacent to silicon material used in an Xray/optical interferometer measurement is the preferred material for a standard lattice comparator crystal. $\mathrm{X}$-ray/optical interferometer measurements have been reported by four national measurement institutes over a span of about 40 years. The silicon material used in the X-ray/optical interferometers came from a variety of sources with different impurity and defect concentrations. Over the years, the crystals improved in perfection, and the measurement apparatus improved in sophistication and accuracy.

In 1973, the National Bureau of Standards (NBS; now NIST) published the first X-ray/optical interferometer (XROI) measurement value for the lattice spacing of a Si crystal produced by Dow Chemical. ${ }^{1}$ The relative uncertainty of this measurement was $3 \times 10^{-7}[19,20]$.

In 1981, the Physikalisch-Technische Bundesanstalt (PTB) reported an X-ray/optical interferometer measurement of the lattice spacing of a Si material produced by Wacker-Chemitronic called WASO 4.2a [21]. The relative uncertainty of this measurement was $6 \times 10^{-8}$. Because the quantity of this material was very limited, the lattice spacing difference between WASO 4.2a and a material called WASO 17 (shortened to W17) was also measured at PTB [22]. A sample of the W17 material was given to NIST, and a lattice comparator crystal was cut and etched. For early lattice comparison measurements, the NIST W17 lattice comparator crystal served as the standard crystal (see Sec. 8.2).

In 1994, the Istituto di Metrologia "G. Colonnetti” (IMGC) published an X-ray/optical interferometer measurement of the lattice spacing of a Si crystal, MO*, grown and purified by Montecatini. The relative uncertainty of this measurement was approximately $3 \times 10^{-8}$ [23].

In 1997, the National Research Laboratory of Metrology (NRLM) reported a lattice spacing value for a Si crystal produced by Shin-Etsu Semiconductor called NRLM3 (shortened to NR3) [24]. The relative uncertainty of this measurement was $5 \times 10^{-8}$.

Additional X-ray/optical interferometer measurements were reported for the PTB WASO 4.2a crystal in 2007 [25] and 2009 [26], for the IMGC MO* crystal in 2004 [27, 28], 2007 [25], and 2009 [26], and for the National Metrology Institute of Japan (NMIJ; formerly NRLM) NR3 crystal in 2004 [27, 28]. The 2009 measurements were performed at the Istituto Nazionale di Ricerca Metrologica (INRIM; formerly IMGC) using an improved apparatus that is briefly described later in this section.

In conjunction with a research project to determine the Avogadro constant, an ingot of hyperpure floatzone natural silicon crystal was produced by Wacker-Siltronic (Germany) in 1995. The ingot was approximately $165 \mathrm{~cm}$ long and $100 \mathrm{~mm}$ in diameter, and it was grown with slight nitrogen doping to

${ }^{1}$ Certain commercial equipment, instruments, or materials are identified in this paper to foster understanding. Such identification does not imply recommendation or endorsement by the National Institute of Standards and Technology, nor does it imply that the materials or equipment identified are necessarily the best available for the purpose. 
prevent precipitation of vacancies and self-interstitials. The concentrations of impurities, vacancies, and self-interstitials of this ingot, called WASO 04 (shortened to W04), were carefully studied [29]. The lattice parameter of the W04 material was first determined by combining lattice comparison measurements $[3,30]$ with the absolute lattice spacing values of the WASO 4.2a and NR3 materials [29, 31]. The relative uncertainty of the lattice parameter of the W04 material was dominated by the uncertainty of the WASO 4.2a and NR3 measurements given earlier herein.

Although eventually a highly enriched ${ }^{28} \mathrm{Si}$ crystal was produced for the determination of the Avogadro constant, the W04 ingot was used to provide proof of the procedures for the determination of the Avogadro constant by the X-ray crystal density method. The W04 ingot was cut into portions and distributed to national measurement institutes that participated in the determination of the Avogadro constant. Two Xray/optical interferometers specimens were cut from the $87 \mathrm{~cm}$ position of the ingot, and absolute lattice spacing measurements were performed at INRIM using a significantly improved apparatus. The displacement of the movable crystal was extended to $5 \mathrm{~cm}$ with nanoradian alignment and nanometer straightness [32, 33]. The results from the two interferometers were in excellent agreement, with a relative uncertainty of $5 \times 10^{-9}$, which is nearly an order of magnitude more accurate than earlier lattice parameter measurements. At the $87 \mathrm{~cm}$ position:

W04 $d_{220}=192.0155702(10) \times 10^{-12} \mathrm{~m}$ at $22.5^{\circ} \mathrm{C}$ and $0 \mathrm{~Pa}$ (vacuum) [4, 32, 33]. The X-ray/optical interferometer measurements were performed near $22.5^{\circ} \mathrm{C}$ and at $0 \mathrm{~Pa}$. Corrections to account for small deviation from $22.5^{\circ} \mathrm{C}$ are described later in this section.

NIST received a sample with $3 \mathrm{~cm}$ thickness from the $12 \mathrm{~cm}$ to $15 \mathrm{~cm}$ region and a sample with $20 \mathrm{~cm}$ thickness from the $123 \mathrm{~cm}$ to $143 \mathrm{~cm}$ region from the W04 ingot. Lattice comparator crystals were cut and etched from material at the $12 \mathrm{~cm}$, the $123 \mathrm{~cm}$, and the $143 \mathrm{~cm}$ positions. The crystal from the $143 \mathrm{~cm}$ position has been used as the standard lattice comparator crystal for comparisons with ${ }^{28} \mathrm{Si}$ samples and for some of the lattice comparisons reported by NIST. By taking into account the variation of the carbon, oxygen, and nitrogen concentrations along the W04 boule, the absolute lattice spacing of the NIST-W04 (shortened to NW04) standard lattice comparator crystal from the $143 \mathrm{~cm}$ position was determined to be: NW04 $d_{220}=192.0155696(10) \times 10^{-12} \mathrm{~m}$ at $22.5^{\circ} \mathrm{C}$ and $0 \mathrm{~Pa}$ [4].

In this paper, all of the lattice parameter values determined for previously unknown samples are traceable to the particular NW04 $d_{220}$ lattice comparator standard or the W04 boule. Transfer crystals are used to link the unknown samples to the W04 boule as described in the next section.

Crystals for which the lattice spacings were determined in this paper are likely to be used at various temperatures and atmospheric pressures. Thus, the reported lattice spacings may need to be adjusted for thermal expansion and atmospheric compressibility. The thermal expansion coefficients for natural silicon are given in Ref. [34]:

$$
\frac{\left(d_{t}-d_{t_{0}}\right)}{d_{t_{0}}}=\alpha_{0}\left(t-t_{0}\right)+\alpha_{1}\left(t-t_{0}\right)^{2}
$$

where $t$ and $t_{0}$ are in ${ }^{\circ} \mathrm{C}, \alpha_{0}=2.5554(2) \times 10^{-6} \mathrm{~K}^{-1}$, and $\alpha_{1}=4.58(4) \times 10^{-9} \mathrm{~K}^{-2}$.

The compressibility of silicon by atmospheric pressure is calculated by $\left(d_{\mathrm{p}}-d_{\mathrm{vac}}\right) / d_{\mathrm{vac}}=-\varepsilon p$, where $p$ is the pressure in Pa. Values for $\varepsilon$ have been determined from interferometric measurements of the length change, $\varepsilon=3.337(50) \times 10^{-12} \mathrm{~Pa}^{-1}$ [34], and calculated from measurements of the elastic moduli, $\varepsilon=$ $3.406(10) \times 10^{-12} \mathrm{~Pa}^{-1}$ [35]. The elastic moduli were calculated from ultrasonic wave velocities. At present, there is no clear explanation for the $2 \%$ difference in these values. Differences in the silicon samples used in the two methods (defects, impurities, dislocations) may be a possible explanation. For the interferometric measurements, the silicon sample was high purity and free of dislocations and defects. Silicon samples used in the earlier elastic moduli measurements were only described as high-purity single crystals. The compressibility for $p=101325 \mathrm{~Pa}$ ( 1 atmosphere) is $\left(d_{\mathrm{p}}-d_{\mathrm{vac}}\right) / d_{\mathrm{vac}}=-3.381(51) \times 10^{-7}$ (from interferometric measurements) and $-3.451(10) \times 10^{-7}$ (from elastic moduli). These two numbers differ by 7 $\times 10^{-9}$, which is an unacceptably large discrepancy for lattice parameter values associated with fundamental constants. However, for diffraction crystal lattice parameter values, where the relative uncertainty of angle measurements is typically a few tens in $10^{-8}$, this discrepancy and the uncertainty of the compressibility coefficient add only minor contributions to the total uncertainty. Because the compressibility coefficient 
determined from interferometric measurements used a silicon sample similar to the samples measured in this report, we recommend $\varepsilon=3.337(50) \times 10^{-12} \mathrm{~Pa}^{-1}$.

Table 1 provides a summary of the standard crystals used in this paper.

Table 1. Summary of standard crystals and their lattice spacing value at $22.5^{\circ} \mathrm{C}$ and 0 Pa used in this paper

\begin{tabular}{|c|c|c|c|c|}
\hline $\begin{array}{c}\text { Standard } \\
\text { Crystal }\end{array}$ & $d_{220}\left(\right.$ at $22.5^{\circ} \mathrm{C}$ and 0 Pa) & $\begin{array}{c}\text { Original } \\
\text { Material }\end{array}$ & Measurement Procedure & References \\
\hline W04 & $192.0155702(10) \times 10^{-12} \mathrm{~m}$ & WASO 04 & $\begin{array}{c}\text { X-ray/optical interferometer } \\
\text { at INRIM (87 cm position) }\end{array}$ & [4, 32, 33] \\
\hline NW04 & $192.0155696(10) \times 10^{-12} \mathrm{~m}$ & WASO 04 & $\begin{array}{c}\text { X-ray/optical interferometer } \\
\text { at INRIM (143 cm position) }\end{array}$ & [4] \\
\hline
\end{tabular}

\subsection{Transfer Crystals}

Some of the lattice parameter values in this paper are directly linked to the W04 material through a comparison of the NW04 standard to the material for which the lattice parameter is unknown. Other lattice parameter values are linked to the W04 material through two comparisons using transfer crystals. The three transfer crystals that are used in this paper have already been identified in the previous section: W17, MO*, and NR3. Samples from these three materials have been compared to a sample from W04 at PTB. Other samples from the W17, MO*, and NR3 materials have been compared to crystals for which the lattice spacings are unknown at NIST. By combining the PTB and NIST lattice comparisons, the crystals for which the lattice spacings are unknown are linked to the W04 material. For the W04 sample used in the PTB comparisons, we use the X-ray/optical interferometer W04 $d_{220}$ absolute value at the $87 \mathrm{~cm}$ position given in Table 1. Because of likely small differences between the comparison samples used at PTB and NIST, the relative uncertainties for measurements traceable to the W04 $d_{220}$ value are increased by $25 \times$ $10^{-9}$.

\subsection{Crystals Under Investigation}

In this study, the lattice spacings were determined of high-quality silicon material obtained in six acquisitions. The suppliers of the material were Wacker (four distinct lots), Solar Energy Research Institute (SERI), and Topsil Semiconductor, Denmark. The lattice spacing results are presented in Sec. 4 through 8, in which the material is identified as WS1 (Wacker), ILL (SERI), WS2 (Wacker), WS3-PBD (Wacker), WS3-SRM (Wacker), WS4-SRM (Wacker), and TS-SRM (Topsil Semiconductor). The concentration of possible impurities in the six acquisitions was not included in this study.

As stated in the introduction, one of the main goals of the comparison measurements is lattice spacing values for crystals that are being used in diffraction instruments to measure X-ray and gamma-ray wavelengths. In most cases, the diffraction and lattice comparison crystals are cut from adjacent parts of the silicon material. Although the distribution of impurity concentrations within a particular silicon material was not included in this study, the close proximity of the diffraction and lattice comparison crystals minimizes possible variations due to impurity concentrations.

\section{Crystals for the NIST Vacuum Double Crystal and Gamma-Ray Spectrometers}

A boule of high-quality silicon was purchased from Wacker in approximately 1985. Because four of the six silicon acquisitions came from Wacker, this material was named WS1 and was used as the feedstock for diffraction crystals used in the NIST VDCS and at the high-resolution flat-crystal gamma-ray (GAMS4) facility at the ILL. Both of these installations accurately measure diffraction angles, which, when combined with the lattice spacing of the diffracting crystals, lead to accurate wavelength values [36-39] traceable to the definition of the meter. Detailed descriptions of the NIST VDCS and the GAMS4 facility can be found in Ref. [6] and Ref. [8], respectively. The NIST lattice comparator was used to compare a sample of the WS1 material to the NW04 standard crystal and to the transfer crystals that are linked to the W04 standard. 
Three pairs of diffraction crystals were cut from the WS1 material for the NIST VDCS instrument. These three pairs of crystals had different orientations (planes parallel to the surface of the crystal), providing the NIST VDCS with a pair of Si(111), a pair of Si(220), and a pair of Si(311) measurement crystals. The lattice spacing comparison measurements used the $\mathrm{Si}(220)$ planes in transmission. Using the cubic structure of the silicon crystal, the lattice parameter $a$ was determined from the $\mathrm{Si}(220)$ lattice spacing and used to obtain lattice spacings of the other planes via

$$
d_{h k l}=\frac{a}{\sqrt{h^{2}+k^{2}+l^{2}}},
$$

where $d$ is the lattice spacing; $a$ the lattice parameter; and $h, k$, and $l$ are the Miller indices.

Six gamma-ray diffraction crystals, using $\mathrm{Si}(220)$ in transmission, were cut from the WS1 silicon with thicknesses of $1.6 \mathrm{~mm}, 2.7 \mathrm{~mm}, 4.4 \mathrm{~mm}$, and $6.9 \mathrm{~mm}$ for the GAMS4 facility. Duplicate crystals were made for each of the two thinnest dimensions to bring the total to six. A drawing of the gamma-ray crystal and a list of the available crystals are given in Ref. [8].

Two lattice comparator crystals were cut from the WS1 material and etched to remove surface damage. The feedstock for one of the lattice comparator crystals, called WS1A, was adjacent to material used for the $6.9 \mathrm{~mm}$ gamma-ray crystal. The location of the other crystal, called WS1B, relative to the VDCS and the gamma-ray crystals is unknown. The lattice spacing difference between the NW04 standard crystal and each of these crystals was measured in September 2016. The data included 129 profiles of the NW04 standard, 77 profiles of the WS1A crystal, and 50 profiles of the WS1B crystal. The measured lattice spacing differences are: $\left(d_{\mathrm{WS} 1 \mathrm{~A}}-d_{\mathrm{NW} 04}\right) / d_{\mathrm{NW} 04}=-14(3) \times 10^{-9}$ and $\left(d_{\mathrm{WS} 1 \mathrm{~B}}-d_{\mathrm{NW} 04}\right) / d_{\mathrm{NW} 04}=-25(9) \times 10^{-9}$. The uncertainties are the standard deviation of repeated data sets with the WS1A and WS1B crystals. The two values are consistent within the uncertainties, but the two crystals may have slightly different lattice spacings because they were taken from different locations in the WS1 boule. To obtain a lattice spacing value for the WS1 material, we chose to average these two lattice spacing differences to obtain $\left(d_{\mathrm{WS} 1}-\right.$ $\left.d_{\mathrm{NW} 04}\right) / d_{\mathrm{NW} 04}=-20(9) \times 10^{-9}$. The relative uncertainty was increased by $25 \times 10^{-9}$ to take into account possible lattice spacing variations in the WS1 material. In Table 2, the lattice spacing difference and the NW04 lattice spacing value are combined to obtain a value for the WS1 $d_{220}$.

Table 2. Calculation of the WS1 $d_{220}$ value (scenario 1).

\begin{tabular}{|l|l|}
\hline $\mathrm{NW} 04 d_{220} t=22.5^{\circ} \mathrm{C}, p=0 \mathrm{~Pa}$ & $192.0155696(10) \times 10^{-12} \mathrm{~m}$ \\
\hline$\left(d_{\mathrm{W} 1}-d_{\mathrm{NW} 04}\right) / d_{\mathrm{NW} 04}$ & $-20(9) \times 10^{-9}$ \\
\hline$\left(d_{\mathrm{W} 1}-d_{\mathrm{NW} 04}\right) / d_{\mathrm{NW} 04}($ combined uncertainty) & $-20(27) \times 10^{-9}$ \\
\hline $\mathrm{WS} 1 d_{220} t=22.5^{\circ} \mathrm{C}, p=0 \mathrm{~Pa}$ & $192.0155658(52) \times 10^{-12} \mathrm{~m}$ \\
\hline
\end{tabular}


Table 3. Calculation of the WS1 $d_{220}$ value (scenario 2)

\begin{tabular}{|c|c|c|c|}
\hline $\begin{array}{c}\mathrm{W} 04 d_{220} \\
t=22.5^{\circ} \mathrm{C}, p=0 \mathrm{~Pa}\end{array}$ & \multicolumn{3}{|c|}{$192.0155702(10) \times 10^{-12} \mathrm{~m}$} \\
\hline Transfer silicon (TS) & MO* & NR3 & W17 \\
\hline$\left(d_{\mathrm{WS} 1}-d_{\mathrm{TS}}\right) / d_{\mathrm{TS}}$ & $56(12) \times 10^{-9}$ & $10(12) \times 10^{-9}$ & $-29(10) \times 10^{-9}$ \\
\hline$\left(d_{\mathrm{TS}}-d_{\mathrm{W} 04}\right) / d_{\mathrm{W} 04}$ & $-103(12) \times 10^{-9}$ & $-23(6) \times 10^{-9}$ & $22(10) \times 10^{-9}$ \\
\hline$\left(d_{\mathrm{WS} 1}-d_{\mathrm{W} 04}\right) / d_{\mathrm{W} 04}$ & $-48(17) \times 10^{-9}$ & $-13(14) \times 10^{-9}$ & $-7(14) \times 10^{-9}$ \\
\hline Average $\left(d_{\mathrm{WS} 1}-d_{\mathrm{W} 04}\right) / d_{\mathrm{W} 04}$ & \multicolumn{3}{|c|}{$-23(22) \times 10^{-9}$} \\
\hline $\begin{array}{c}\text { Average }\left(d_{\mathrm{wS} 1}-d_{\mathrm{w} 04}\right) / d_{\mathrm{w} 04} \\
\text { (combined uncertainty) }\end{array}$ & \multicolumn{3}{|c|}{$-23(33) \times 10^{-9}$} \\
\hline $\begin{array}{c}\text { WS1 } d_{220} \\
t=22.5^{\circ} \mathrm{C}, p=0 \mathrm{~Pa}\end{array}$ & \multicolumn{3}{|c|}{$192.0155659(64) \times 10^{-12} \mathrm{~m}$} \\
\hline
\end{tabular}

An alternate approach to the lattice spacing of the WS1 material connects the WS1 material to the W04 boule through lattice comparisons made at PTB and NIST. Eight crystals from different boules, suppliers, and national laboratories are involved: four crystals at PTB-W04, MO*, NR3, and W17; four crystals at NIST-WS1A, MO*, NR3, and W17. The MO*, NR3, and W17 samples were supplied by INRIM, NMIJ, and PTB, respectively. At PTB, the W04 sample was compared to the MO*, NR3, and W17 samples supplied to PTB [30]. At NIST, the WS1A sample was compared to the MO*, NR3, and N17 samples supplied to NIST. The NIST measurements were completed from October 1998 to March 1999. There are likely small differences between the samples of the transfer crystals, MO*, NR3, and W17, used at NIST and PTB. Similarly, the W04 sample used in the comparisons at PTB likely differs slightly from the W04 $d_{220}$ standard given earlier herein. The input values for the determination of the WS1 $d_{220}$ are given in Table 3 . The relative uncertainties of the average $\left(d_{\mathrm{WS} 1}-d_{\mathrm{W} 04}\right) / d_{\mathrm{W} 04}$ value were increased by $25 \times 10^{-9}$ to account for the variability of the MO*, NR3, W17, and W04 samples.

The excellent agreement between the two routes to the WS1 $d_{220}$ value provides confidence in the lattice comparison measurements at both PTB and NIST. A value for the lattice spacing of the WS1 material was published in 2006 in Ref. [39]. However, that value was based on an unpublished lattice spacing value from "CODATA Recommended Values of the Fundamental Physical Constants: 1998” [40]. Although, the published 2006 WS1 lattice spacing, $d_{220}=192.0155745(96) \times 10^{-12}$, agrees within the uncertainty with the more accurate values reported here, the value in Table 2 is preferred because it relies on only one lattice comparison.

\section{Other Crystals for the Gamma-Ray Spectrometer}

A small quantity of high-quality silicon was given to NIST by Solar Energy Research Institute (SERI), now the National Renewable Energy Laboratory (NREL), in the early 1980s. Two diffraction crystals (2.5 $\mathrm{mm}$ thick) were cut from this material and used to measure gamma-ray wavelengths at the ILL. A crystal appropriate for the lattice comparator was cut from material adjacent to the $2.5 \mathrm{~mm}$ crystals. See Ref. [8] for a drawing of the gamma-ray crystals. A lattice comparison measurement involving the silicon material from SERI is included in the 2014 CODATA recommended values of the fundamental physical constants, where the material is called ILL [15]. We also use the ILL designation for this material.

The lattice parameter of the ILL material can be related to the W04 standards using two paths that are similar to those described in the previous section for the WS1 material. The first scenario begins with the lattice spacing of the NW04 crystal and uses the WS1 to NW04 comparison presented in the previous section and the ILL to WS1 comparison in Ref. [39]. The ILL to WS1 comparison was completed in December 2000 to January 2001. Numerical values for the lattice comparisons are included in Table 4, where an additional relative uncertainty of $25 \times 10^{-9}$ was introduced in the $\left(d_{\mathrm{ILL}}-d_{\mathrm{NW} 04}\right) / d_{\mathrm{NW} 04}$ uncertainty to account for the variability of the samples. 
Table 4. Calculation of the ILL $d_{220}$ value (scenario 1).

\begin{tabular}{|c|c|}
\hline $\mathrm{NW} 04 d_{220} t=22.5^{\circ} \mathrm{C}, p=0 \mathrm{~Pa}$ & $192.0155696(10) \times 10^{-12} \mathrm{~m}$ \\
\hline$\left(d_{\mathrm{ILL}}-d_{\mathrm{WS} 1}\right) / d_{\mathrm{WS} 1}$ & $40(10) \times 10^{-9}$ \\
\hline$\left(d_{\mathrm{WS} 1}-d_{\mathrm{NW} 04}\right) / d_{\mathrm{NW} 04}$ & $-20(9) \times 10^{-9}$ \\
\hline$\left(d_{\mathrm{ILL}}-d_{\mathrm{NW} 04}\right) / d_{\mathrm{NW} 04}$ & $20(14) \times 10^{-9}$ \\
\hline $\begin{array}{c}\left(d_{\mathrm{ILL}}-d_{\mathrm{NW} 04}\right) / d_{\mathrm{NW} 04}(\text { combined } \\
\text { uncertainty) }\end{array}$ & $20(29) \times 10^{-9}$ \\
\hline $\mathrm{ILL} d_{220} t=22.5^{\circ} \mathrm{C}, p=0 \mathrm{~Pa}$ & $192.0155735(56) \times 10^{-12} \mathrm{~m}$ \\
\hline
\end{tabular}

The second approach is based on the absolute lattice parameter of the W04 boule and uses the three PTB lattice comparisons that were included in the previous section [30]. At NIST, the ILL sample was compared to the MO*, NR3, and W17 samples in July 1998, and the lattice spacing differences were published in Ref. [38]. Values for all six lattice comparisons are included in Table 5. Similar to the WS1 material, the relative uncertainty of the average $\left(d_{\mathrm{ILL}}-d_{\mathrm{W} 04}\right) / d_{\mathrm{W} 04}$ value was increased by $25 \times 10^{-9}$ to account for the variability of the MO*, NR3, W17, and W04 samples.

These two ways of determining the lattice spacing of the ILL silicon involve nine lattice comparator crystals and eight lattice parameter comparisons made at two laboratories. The two values, which agree very well, were averaged to obtain a final value for the lattice parameter of the ILL material: ILL $d_{220}=$ $192.0155721(64) \times 10^{-12} \mathrm{~m}$ at $22.5^{\circ} \mathrm{C}$ and $0 \mathrm{~Pa}$.

In two earlier publications, numerical values for the ILL lattice parameter were presented. One of these values was based on less accurate absolute lattice spacing values from PTB, INRIM, and NMIJ [38]. The other one was based on an unpublished lattice spacing value from the "CODATA Recommended Values of the Fundamental Physical Constants: 1998” [39, 40]. Within the uncertainties, the earlier published values agree with the ILL $d_{220}$ value given here. However, this new value is preferred because it is linked to a more accurate absolute lattice parameter measurement.

Table 5. Calculation of the ILL $d_{220}$ value (scenario 2).

\begin{tabular}{|c|c|c|c|}
\hline $\begin{array}{c}\text { W04 } d_{220} \\
t=22.5^{\circ} \mathrm{C}, p=0 \mathrm{~Pa}\end{array}$ & \multicolumn{3}{|c|}{$192.0155702(10) \times 10^{-12} \mathrm{~m}$} \\
\hline Transfer silicon (TS) & $\mathrm{MO}^{*}$ & $\mathrm{NR} 3$ & $-8(10) \times 10^{-9}$ \\
\hline$\left(d_{\mathrm{ILL}}-d_{\mathrm{TS}}\right) / d_{\mathrm{TS}}$ & $86(10) \times 10^{-9}$ & $34(10) \times 10^{-9}$ & $22(10) \times 10^{-9}$ \\
\hline$\left(d_{\mathrm{TS}}-d_{\mathrm{W} 04}\right) / d_{\mathrm{W} 04}$ & $-103(12) \times 10^{-9}$ & $-23(6) \times 10^{-9}$ & $14(14) \times 10^{-9}$ \\
\hline$\left(d_{\mathrm{ILL}}-d_{\mathrm{W} 04}\right) / d_{\mathrm{W} 04}$ & $-17(16) \times 10^{-9}$ & $11(12) \times 10^{-9}$ & $3(17) \times 10^{-9}$ \\
\hline Average $\left(d_{\mathrm{ILL}}-d_{\mathrm{W} 04}\right) / d_{\mathrm{W} 04}$ & \multicolumn{3}{|c|}{$3(30) \times 10^{-9}$} \\
\hline $\begin{array}{c}\text { Average }\left(d_{\mathrm{ILL}}-d_{\mathrm{W} 04}\right) / d_{\mathrm{W} 04} \\
(\text { combined uncertainty })\end{array}$ & $192.0155707(59) \times 10^{-12} \mathrm{~m}$ \\
\hline ILL $d_{220} t=22.5^{\circ} \mathrm{C}, p=0 \mathrm{~Pa}$ & \multicolumn{3}{|c}{} \\
\hline
\end{tabular}

\section{Crystals for the LKB Vacuum Double Crystal Spectrometer}

The vacuum double crystal spectrometer (DCS) at the LKB in Paris, France, was built to perform precision measurements on X-ray transitions in highly charged ions to test quantum electrodynamics (QED) theories [41]. The DCS was designed and built to operate in vacuum and to be attached to an Electron Cyclotron Resonance Ion Source (ECRIS) to directly observe the highly charged ion plasma [42]. The DCS described in [9], in addition to providing reference-free line energy measurements with a relative 
accuracy of $1 \times 10^{-6}$, can also be a tool to determine transition probabilities and ion temperatures inside a highly charged ion plasma [43].

The crystals for the DCS and the associated lattice comparison measurement were described in a recent publication [9]. In addition, an absolute lattice parameter value traceable to the NW04 standard was provided in Table 1 of that publication. Only a few details are included here in order to provide a more complete record of NIST lattice comparator activities.

The feedstock for the DCS silicon diffraction crystals was purchased from Wacker-Siltronic by the University of Missouri and then transferred to NIST around 1990. This feedstock is designated WS2. Four LKB diffraction crystals were cut from the WS2 material, along with a lattice comparator diffraction crystal. The WS2 lattice comparator diffraction crystal was compared to the NW04 standard in January 2006 with the following result: $\left(d_{\mathrm{WS} 2}-d_{\mathrm{NW} 04}\right) / d_{\mathrm{NW} 04}=-23(5) \times 10^{-9}$. Before adjusting the absolute NW04 lattice spacing by the measured lattice spacing difference between the WS2 material and the NW04 standard, an uncertainty of $25 \times 10^{-9}$ was included to account for possible sample variability. In Ref. [9], a relative uncertainty of $10 \times 10^{-9}$ was included to account for possible sample variability, which we now believe was underestimated. The determination of the lattice spacing of the WS2 material is summarized in Table 6.

Table 6. Calculation of the WS2 $d_{220}$ value.

\begin{tabular}{|c|c|}
\hline NW04 $d_{220} t=22.5^{\circ} \mathrm{C}, p=0$ Pa & $192.0155696(10) \times 10^{-12} \mathrm{~m}$ \\
\hline$\left(d_{\mathrm{WS} 2}-d_{\mathrm{NW} 04}\right) / d_{\mathrm{NW} 04}$ & $-23(5) \times 10^{-9}$ \\
\hline $\begin{array}{c}\left(d_{\mathrm{WS} 2}-d_{\mathrm{NW} 04}\right) / d_{\mathrm{NW} 04}(\text { combined } \\
\text { uncertainty) }\end{array}$ & $-23(26) \times 10^{-9}$ \\
\hline $\mathrm{WS} 2 d_{220} t=22.5^{\circ} \mathrm{C}, p=0 \mathrm{~Pa}$ & $192.0155651(50) \times 10^{-12} \mathrm{~m}$ \\
\hline
\end{tabular}

\section{Crystals for the NIST Parallel Beam Diffractometer}

The Materials Measurement Science Division of the NIST MML supports a program in X-ray metrology that provides widely used SRMs for powder diffraction. To provide for this, a diffractometer was built to perform SI traceable lattice parameter measurements on powders, single crystals, and the layer spacing of thin film structures. Using suitable reference crystals, it is also capable of measuring X-ray emission spectra in an SI traceable manner. The machine has been under development for some 20 years; however, publications have been relatively recent. Because the optics of the machine provide a parallel incident beam, it is called the parallel beam diffractometer. The machine includes a Rigaku $15 \mathrm{~kW}$ rotating anode X-ray source and a range of optics, including a graded parabolic mirror and two Si Bartels monochromator assemblies of low and high resolution. The goniometer consists of two stacked, Huber 430 rotation stages equipped with Heidenhain RON-905 angle encoders. The machine's goniometer assembly has been calibrated using the circle closure method, which provides SI traceability in angle measurement $[7,44,45]$. The machine is located in the subterranean Building 219 of AML; the space is temperature controlled to $0.01{ }^{\circ} \mathrm{C}$ during measurements. A range of analyzers is also available, and the detector used is typically a Dectris Pilatus 100K X-ray camera. The machine can be set up as a double crystal diffractometer using two channel-cut 3-bounce silicon (440) reference crystals for an SI traceable analysis of emission spectra [46] .

The silicon feedstock for the channel-cut crystals of the PBD and the associated lattice comparator crystals was purchased from Wacker-Siltronic in 2005 primarily as feedstock for the powder diffraction SRMs 640d, 640e, and 640f. Measurements on the variability of the lattice spacing along the boule (boule number 5061 553, $108 \mathrm{~cm}$ long) are included in the next section on SRMs. Although most of this boule, with a total length of $108 \mathrm{~cm}$, was pulverized for use in powder SRMs, a small portion of this material, subboule \#5061 553/090 (see Fig. 7 in next section) was retained and used for the channel-cut crystal. The 
channel-cut crystal and the lattice comparator crystals were cut from a silicon disk that was $24 \mathrm{~mm}$ thick and $102 \mathrm{~mm}$ diameter, as shown in Fig. 2.
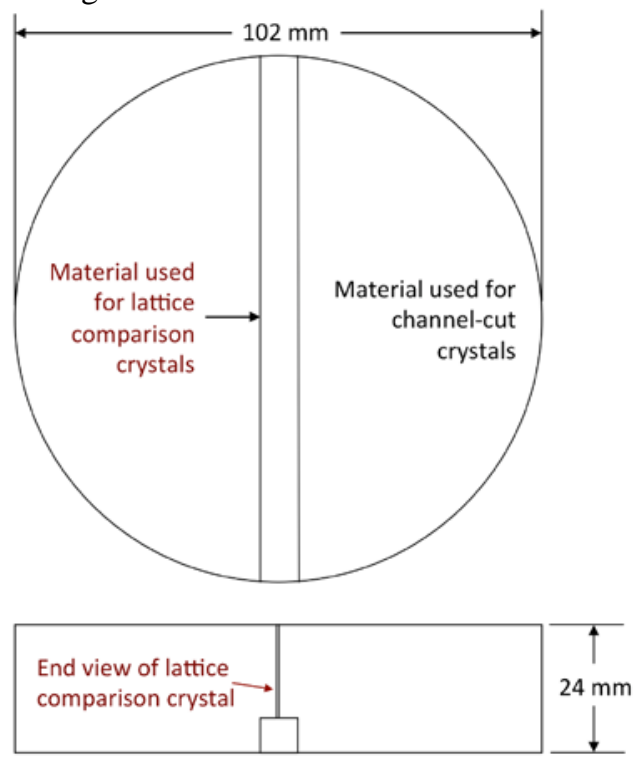

Fig. 2. The cutting plan for the channel-cut and lattice comparator crystals.

For ease of identification, this silicon boule is called WS3, and this particular portion of the WS3 boule is called WS3-PBD. Because the lattice comparator cannot accommodate a crystal that is $102 \mathrm{~cm}$ long, two lattice comparator crystals were made, one $54 \mathrm{~mm}$ long (crystal A) and the other $48 \mathrm{~mm}$ long (crystal B).

The two unknown crystals were compared to the NW04 standard. Each crystal was compared at five locations along the face of the crystal, and several of the measurements were repeated to ensure reproducibility of the data. The comparison of the unknown crystals to the NW04 standard occurred in August and September 2013.

The results of the comparison of the WS3-PBD material to the NW04 standard are given in Table 7 and Fig. 3.

Table 7. Comparison of the WS3-PBD material to the NW04 standard.

\begin{tabular}{|c|c|c|}
\hline $\begin{array}{c}\text { Radial Boule } \\
\text { Position }(\mathrm{mm})\end{array}$ & $\begin{array}{c}\text { Crystal A } \\
\text { or B }\end{array}$ & $\left(d_{\mathrm{WS3}-\mathrm{PBD}}-d_{\mathrm{NW} 04}\right) / d_{\mathrm{NW} 04}$ \\
\hline-47 & A & $2(5) \times 10^{-9}$ \\
\hline-37 & A & $10(5) \times 10^{-9}$ \\
\hline-27 & A & $12(5) \times 10^{-9}$ \\
\hline-17 & A & $9(5) \times 10^{-9}$ \\
\hline-7 & A & $2(5) \times 10^{-9}$ \\
\hline+4 & B & $-11(5) \times 10^{-9}$ \\
\hline+14 & B & $14(7) \times 10^{-9}$ \\
\hline+24 & B & $23(5) \times 10^{-9}$ \\
\hline+34 & B & $15(5) \times 10^{-9}$ \\
\hline+44 & B & $8(5) \times 10^{-9}$ \\
\hline
\end{tabular}




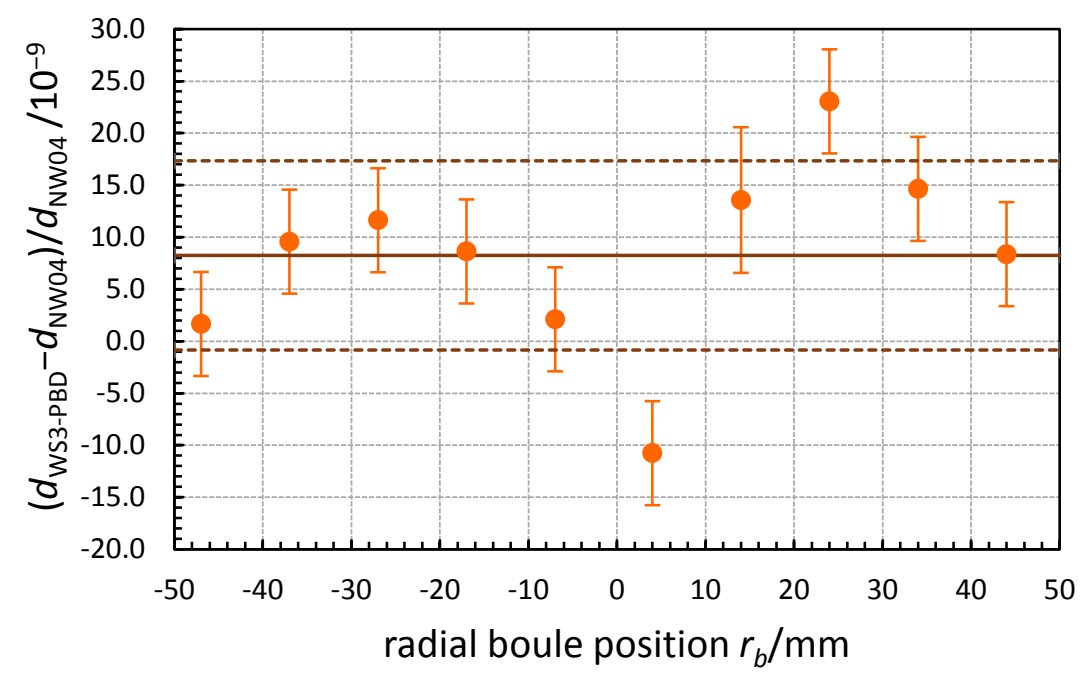

Fig. 3. The relative lattice spacing difference between the WS3-PBD silicon material and the NW04 standard. The solid and dashed lines are the average difference and the uncertainty, respectively.

The radial boule positions, $r_{b}$, are the distance in millimeters from the center of the boule, and the $\left(d_{\mathrm{WS3}-\mathrm{PBD}}-d_{\mathrm{NW} 04}\right) / d_{\mathrm{NW} 04}$ values are the average values for each of the 10 data positions. The average and standard deviation of these 10 values is $\left(d_{\mathrm{WS3}-\mathrm{PBD}}-d_{\mathrm{NW} 04}\right) / d_{\mathrm{NW} 04}=8(9) \times 10^{-9}$. Crystals A and B were supported in a manner similar to that shown in Fig. 6 at the approximate radial positions $-23 \mathrm{~mm}$ and +28 $\mathrm{mm}$, respectively. The distribution of the points in Fig. 3 suggests possible lattice distortion due to gravity, which was not further studied.

Although the measurements in Table 7 are along only one diameter of the WS3-PBD material, the spread in the measurements supports the inclusion of a relative uncertainty term of approximately $25 \times 10^{-9}$ for sample to sample variability. A histogram of the measurement results presented in Table 7 is shown in Fig. 4.

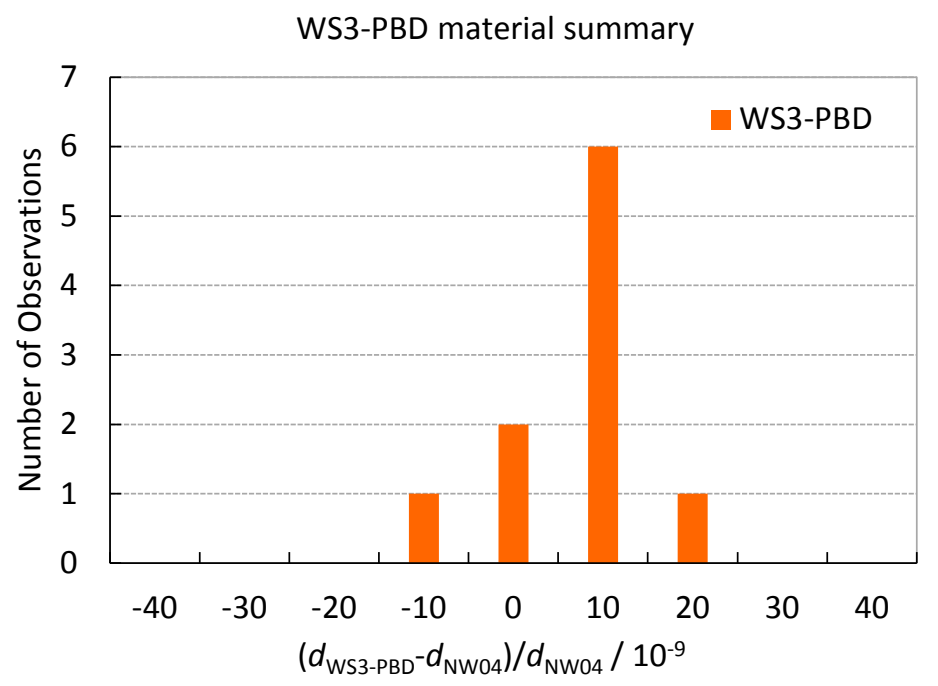

Fig. 4. Histogram of relative lattice spacing measurements for WS3-PBD.

The absolute lattice parameter of the channel-cut crystal used in the NIST PBD was calculated by adjusting the NW04 standard lattice spacing value by the measured lattice spacing difference between the 
WS3-PBD silicon and the NW04 standard. Table 8 contains the numerical values used in these calculations.

Table 8. Calculation of the WS3-PBD material $d_{220}$ value.

\begin{tabular}{|c|c|}
\hline NW04 $d_{220} t=22.5^{\circ} \mathrm{C}, p=0$ Pa & $192.0155696(10) \times 10^{-12} \mathrm{~m}$ \\
\hline$\left(d_{\mathrm{WS} 3-\mathrm{PBD}}-d_{\mathrm{NW} 04}\right) / d_{\mathrm{NW} 04}$ & $8(9) \times 10^{-9}$ \\
\hline$\left(d_{\mathrm{WS} 3-\mathrm{PBD}}-d_{\mathrm{NW} 04}\right) / d_{\mathrm{NW} 04}($ combined uncertainty) & $8(27) \times 10^{-9}$ \\
\hline $\mathrm{WS} 3-\mathrm{PBD} d_{220} t=22.5^{\circ} \mathrm{C}, p=0 \mathrm{~Pa}$ & $192.0155712(52) \times 10^{-12} \mathrm{~m}$ \\
\hline
\end{tabular}

\section{Standard Reference Materials}

The NIST lattice comparator has played a critical role in determining the variability and absolute lattice parameters of single-crystal silicon used to produce powder diffraction SRMs. The feedstock for powder diffraction SRMs has been purchased in kilogram quantities as single-crystal silicon. After characterization with the lattice comparator, the silicon is crushed and jet milled into a powder having a narrow crystallite size distribution with a median of approximately $4 \mu \mathrm{m}$ and a cutoff at $1 \mu \mathrm{m}$. This size range ensures that the powder is optimal for the powder diffraction experiment and displays a minimum level of size broadening. It is then annealed [47] to eliminate crystallographic defects induced by comminution that lead to strain broadening of the profiles. This annealing is performed in gettered argon at $1000^{\circ} \mathrm{C}$; the partial pressure of oxygen is sufficiently low during the annealing process that the surface is oxide free [48]. A uniform native oxide layer forms immediately upon exposure to air.

The powder SRMs themselves are certified in batches, the size of which is determined from the sales rates and an anticipated recertification interval of 5 to 7 years. These batches are typically much smaller than the lots of the single-crystal silicon initially purchased. When the stocks of a given certification are exhausted, a renewal of the SRM is certified with a suffix letter incremented for each renewal. Hence, SRM 640e is the sixth certification of SRM 640, originally certified in 1973. The certification of the powders involves an SI traceable measurement of the lattice parameter [10-14] on the NIST-built divergent beam diffractometer [49]. With these certifications, NIST has always measured a larger lattice parameter from the powders (0.543 $1179 \mathrm{~nm}$ for SRM 640e) than that of bulk single crystals (0.543 $1019 \mathrm{~nm}$ for the SRM 640d, 640e, and 640f raw material, at a temperature of $22.5^{\circ} \mathrm{C}$ and a pressure of $101325 \mathrm{~Pa}$ [atmospheric pressure]). This is due to the fact that the oxide layer is in a state of compression [50] and thus exhibits a hydrostatic tensile stress on the crystallite, expanding its apparent lattice parameter.

Knowledge of the uniformity of the lattice spacing of these large quantities of single-crystal silicon is essential for ensuring high-quality powder diffraction SRMs. The lattice comparator was used to certify two lots of SRM feedstock. In 1997, ten cylinders (30.4 kg) of single-crystal silicon with a diameter of 75 $\mathrm{mm}$ were purchased from Topsil identified as TS-SRM material. In 2005, two boules of single-crystal silicon (eight cylinders, $39.3 \mathrm{~kg}$ ) with a diameter of $102 \mathrm{~mm}$ were acquired from Wacker-Siltronic, named WS3-SRM and WS4-SRM. Samples were taken from the boules (cylinders) of feedstock, and diffraction crystals appropriate for the lattice comparator were shaped with a diamond saw and etched to remove surface damage. 


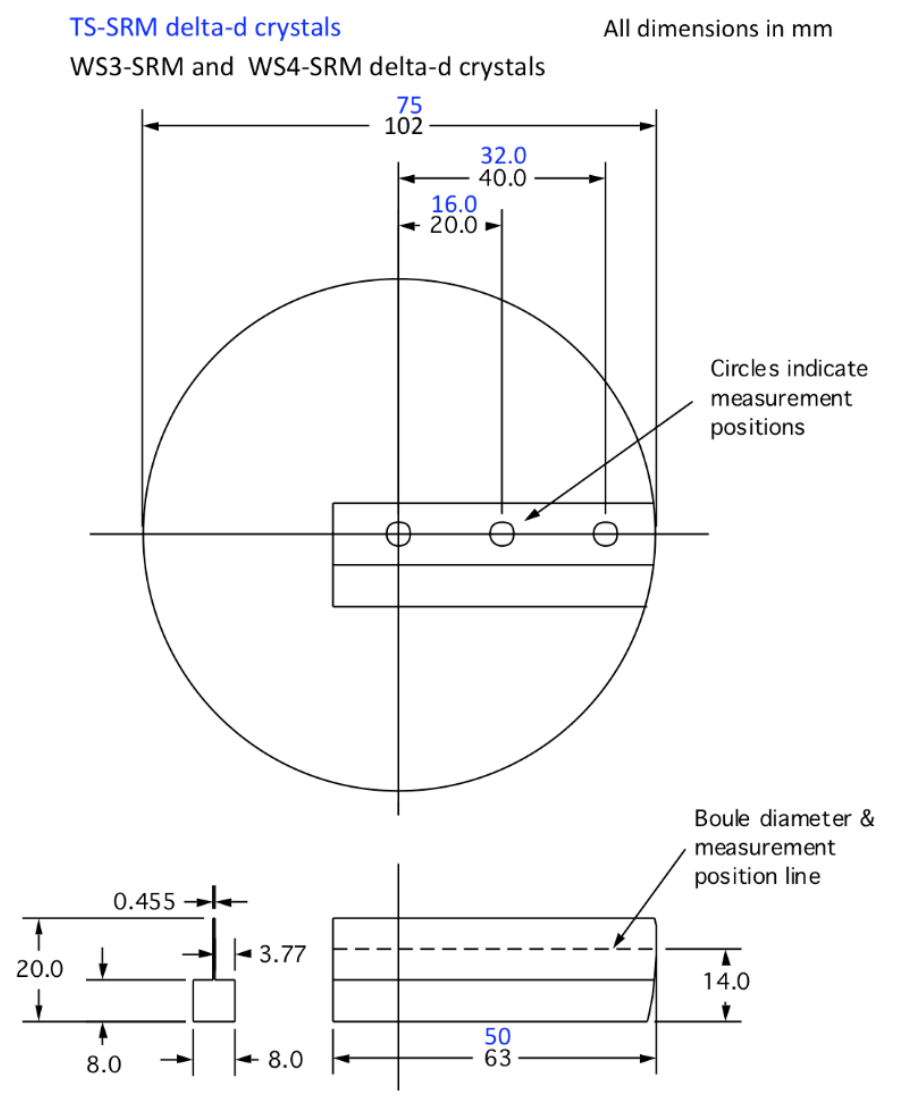

Fig. 5. Cutting plan for the SRM lattice comparator crystals. All dimensions are in millimeters. Black numbers show dimensions for the WS3-SRM and WS4-SRM materials, and blue numbers are valid for the TS-SRM material.

Both the radial variation and longitudinal variation of the lattice parameter in the cylinders were measured. Figure 5 shows the cutting plan for the crystals used for lattice comparison. The crystals were cut from the feedstock to permit lattice comparison along a boule diameter. Figure 6 is a photograph of a lattice comparator crystal from the WS4 silicon material. 


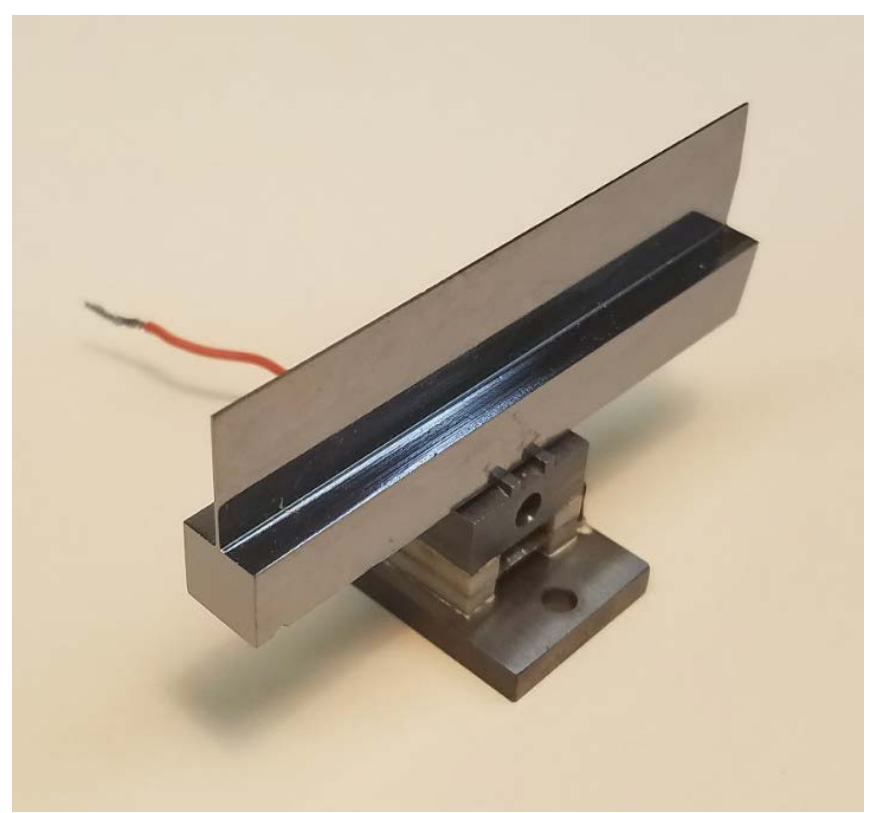

Fig. 6. Photograph of a mounted measurement crystal from the WS4-SRM material.

\subsection{Powder Diffraction SRMs 640d, 640e, and 640f}

The feedstock for the WS3-SRM and WS4-SRM materials was obtained from Wacker-Siltronic. The WS3-SRM and WS4-SRM materials came from boules 5061553 and 5061 495, respectively, which were each about $110 \mathrm{~cm}$ long. Each boule was cut into four cylinders and identified by Wacker-Siltronic with the numbers given in Table 9. The first seven numbers identify the long silicon boule, and the last three numbers give the approximate longitudinal position of the end of the cylinder that is farther from the zero reference end of the long boule. For example, cylinder number 5061 495/092 (about $31 \mathrm{~cm}$ long) is the 61 $\mathrm{cm}$ to $92 \mathrm{~cm}$ portion of the 5061495 boule. The ends of the cylinders were marked to permit identification of the smaller and larger longitudinal positions. Figure 7 shows the relative locations of the sub-boules and the positions from which the measurement crystals were cut.

Table 9. Identification of the Wacker-Siltronic silicon boules and lattice comparator $(\Delta d)$ crystals.

\begin{tabular}{|c|c|c|c|c|}
\hline & $\begin{array}{l}\text { Boule and Cylinder } \\
\text { Numbers }\end{array}$ & Length $(\mathrm{cm})$ & $\begin{array}{c}\Delta d \text { Crystal } \\
\text { Number }\end{array}$ & $\begin{array}{l}\text { Approx. Longitudinal } \\
\text { Location }(\mathrm{cm})\end{array}$ \\
\hline \multirow{5}{*}{$\begin{array}{l}\sum_{1} \\
5 \\
5 \\
5 \\
3\end{array}$} & 5061495 / 030 & 29.1 & 1 & 1 \\
\hline & 5061495 / 060 & 28.8 & 2 & 31 \\
\hline & \multirow{2}{*}{5061495 / 092} & \multirow{2}{*}{30.9} & 3 & 61 \\
\hline & & & 4 & 91 \\
\hline & 5061495 / 107 & 14.8 & 5 & 106 \\
\hline \multirow{6}{*}{$\begin{array}{l}\sum_{1} \\
\omega \\
1 \\
\infty \\
\omega \\
3\end{array}$} & \multirow{2}{*}{5061553 / 035} & \multirow{2}{*}{34.4} & 6 & 1 \\
\hline & & & 7 & 34 \\
\hline & \multirow{2}{*}{5061553 / 070} & \multirow{2}{*}{34.5} & 8 & 36 \\
\hline & & & 9 & 69 \\
\hline & $5061553 / 090$ & 19.1 & 10 & 89 \\
\hline & $5061553 / 108$ & 18.0 & 11 & 107 \\
\hline
\end{tabular}


WS4-SRM

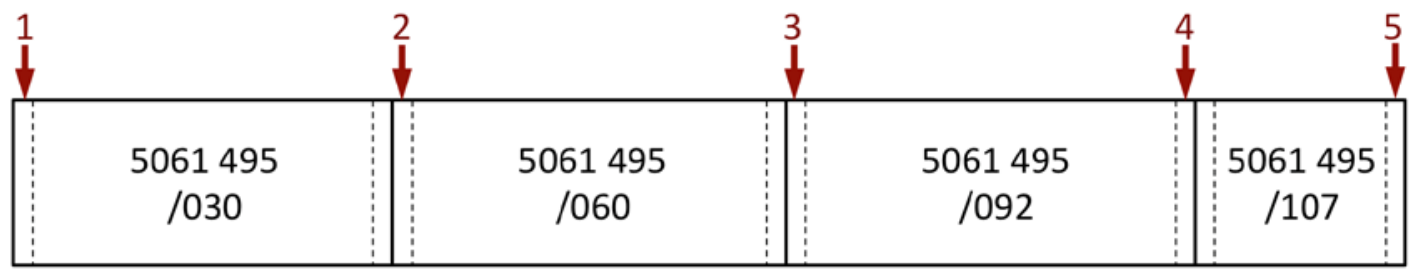

\section{WS3-SRM}

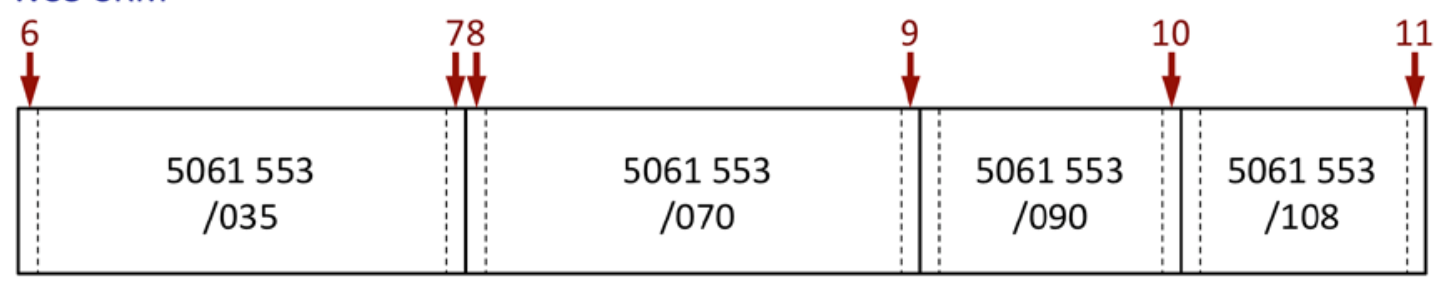

$\mathrm{cm}$

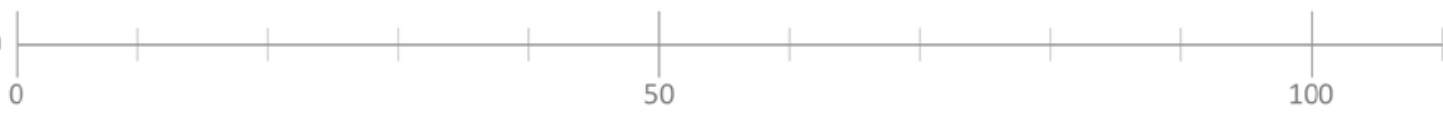

Fig. 7. Relative location (not actual scale) of boules and cutting plan for the Wacker-Siltronic silicon material used for SRMs 640d, 640e, and 640f. The arrows indicate the positions from which the samples for the lattice comparator were produced along with the sample numbers.

Thin disks, $102 \mathrm{~mm}$ in diameter and approximately $10 \mathrm{~mm}$ thick, were cut from each end of the eight cylinders using a circumferential saw. From these 16 thin disks, 11 crystals were cut and etched with a shape as shown in Fig. 5. The crystals are $63 \mathrm{~mm}$ long, and the primary measurement positions are at the center of the boule, $20 \mathrm{~mm}$ from the center of the boule, and $40 \mathrm{~mm}$ from the center of the boule. Lattice comparator crystal identification numbers and approximate longitudinal locations in each of the long boules are given in Table 9, columns 3 and 4, respectively.

The 11 Wacker-Siltronic silicon crystals were compared to the NW04 lattice comparator standard. A Wacker-Siltronic sample and the NW04 standard were mounted on the sample transport slide of the NIST lattice comparator and aligned with respect to the first crystal at each measurement position on the WackerSiltronic sample. The comparison of the Wacker-Siltronic crystals to the NW04 standard took place during approximately 11 weeks in April to July 2006.

The measured relative lattice parameter differences with respect to the NW04 crystal are given in Table 10 and Table 11 for the WS4-SRM and WS3-SRM material, respectively. The $40 \mathrm{~mm}$ position in crystal 8 was not measured because this crystal fractured during preparation, leaving usable crystal areas at $0 \mathrm{~mm}$ and $20 \mathrm{~mm}$. The values are reported for $\left(d_{\mathrm{WS} 4-\mathrm{SRM}}-d_{\mathrm{NW} 04}\right) / d_{\mathrm{NW} 04}$ and $\left(d_{\mathrm{WS3}-\mathrm{SRM}}-d_{\mathrm{NW} 04}\right) / d_{\mathrm{NW} 04}$.

Table 10. Lattice comparison results for the WS4-SRM silicon material (boule 5061 495).

\begin{tabular}{|c|c|c|c|c|}
\hline \multirow{3}{*}{$\begin{array}{c}\Delta d \text { Crystal } \\
\text { Number }\end{array}$} & \multirow{3}{*}{$\begin{array}{c}\text { Approx. } \\
\text { Longitudinal } \\
\text { Location }(\mathrm{cm})\end{array}$} & \multicolumn{3}{|c|}{$\left(d_{\mathrm{WS4} 4 \mathrm{SRM}}-d_{\mathrm{NW} 04}\right) / d_{\mathrm{NW} 04}$} \\
\hline & & \multicolumn{3}{|c|}{ Radial Location from Center } \\
\hline & & $0 \mathrm{~mm}$ & $20 \mathrm{~mm}$ & $40 \mathrm{~mm}$ \\
\hline 1 & 1 & $10(5) \times 10^{-9}$ & $30(5) \times 10^{-9}$ & $10(5) \times 10^{-9}$ \\
\hline 2 & 31 & $18(5) \times 10^{-9}$ & $-43(5) \times 10^{-9}$ & $0(6) \times 10^{-9}$ \\
\hline 3 & 61 & $10(5) \times 10^{-9}$ & $-6(5) \times 10^{-9}$ & $-6(5) \times 10^{-9}$ \\
\hline 4 & 91 & $-1(5) \times 10^{-9}$ & $-4(5) \times 10^{-9}$ & $-6(5) \times 10^{-9}$ \\
\hline 5 & 106 & $6(5) \times 10^{-9}$ & $22(5) \times 10^{-9}$ & $-16(5) \times 10^{-9}$ \\
\hline \multicolumn{2}{|c|}{ Average of all the measurements } & \multicolumn{3}{|c|}{$2(17) \times 10^{-9}$} \\
\hline
\end{tabular}


Table 11. Lattice comparison results for the WS3-SRM silicon material (boule 5061 553).

\begin{tabular}{|c|c|c|c|c|}
\hline \multirow{2}{*}{$\begin{array}{c}\Delta d \text { Crystal } \\
\text { Number }\end{array}$} & $\begin{array}{c}\text { Approx. } \\
\text { Longitudinal } \\
\text { Location }(\mathrm{cm})\end{array}$ & \multicolumn{3}{|c|}{$\left(d_{\mathrm{WS3} \text {-SRM }}-d_{\mathrm{NW} 04}\right) / d_{\mathrm{NW} 04}$} \\
\cline { 3 - 5 } & 1 & $0 \mathrm{~mm}$ & $20 \mathrm{~mm}$ & $40 \mathrm{~mm}$ \\
\hline 6 & 34 & $35(5) \times 10^{-9}$ & $20(5) \times 10^{-9}$ & $7(5) \times 10^{-9}$ \\
\hline 7 & 36 & $14(5) \times 10^{-9}$ & $28(5) \times 10^{-9}$ & $10(5) \times 10^{-9}$ \\
\hline 8 & 69 & $33(5) \times 10^{-9}$ & $36(5) \times 10^{-9}$ & \\
\hline 9 & 89 & $5(5) \times 10^{-9}$ & $21(5) \times 10^{-9}$ & $5(5) \times 10^{-9}$ \\
\hline 10 & 107 & $1(5) \times 10^{-9}$ & $15(5) \times 10^{-9}$ & $-11(5) \times 10^{-9}$ \\
\hline 11 & $11(5) \times 10^{-9}$ & $15(5) \times 10^{-9}$ & $1(5) \times 10^{-9}$ \\
\hline \multicolumn{3}{|l|}{} & \multicolumn{3}{|c|}{$14(13) \times 10^{-9}$} \\
\hline
\end{tabular}

One measurement (crystal 2, $20 \mathrm{~mm}$ from center) differs significantly from other neighboring measurements in boule 5061 495. In order to determine if this result was due to a possible measurement error, an additional lattice comparison measurement was made at the $23 \mathrm{~mm}$ radial location on crystal 2. The measurements at $20 \mathrm{~mm}$ and $23 \mathrm{~mm}$ differ by only $3 \times 10^{-9}$, and the result given in Table 10 (crystal 2, $20 \mathrm{~mm}$ from center) is the average of these two measurements. These measurements suggest that there is a localized variation in lattice spacing of about $40 \times 10^{-9}$ at this position in the WS4-SRM material. No further investigation of this anomaly was conducted.

Figure 8 shows the average $\Delta d / d$ value measured in the three radial positions for each longitudinal position, $l_{b}$, considered in the two boules. This gives preliminary information about the longitudinal variability of the lattice spacing within a given silicon ingot.

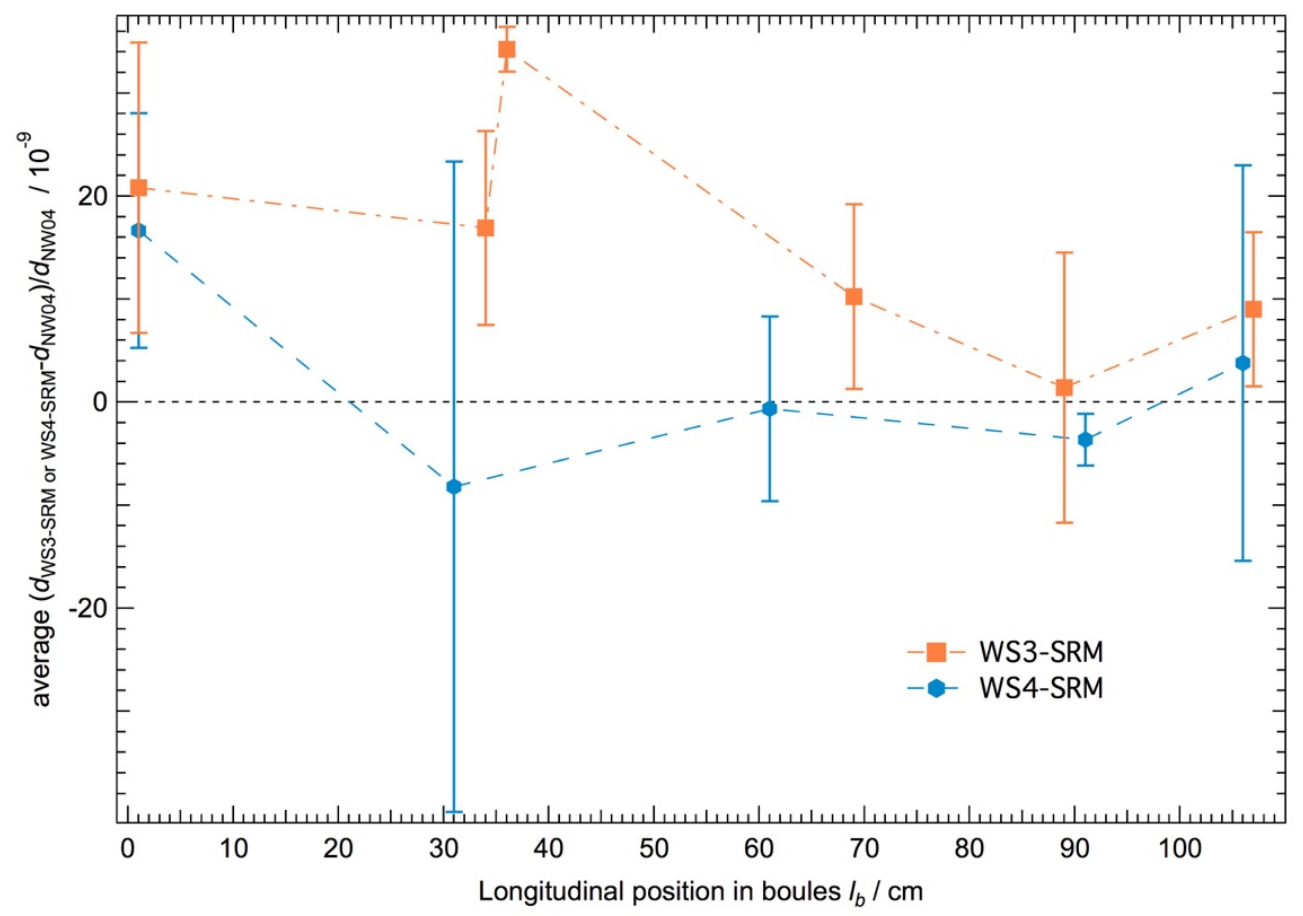

Fig. 8. Average $\Delta d / d$ results for the WS3-SRM and WS4-SRM materials as a function of longitudinal position in the boules. The averages were calculated from Tables 10 and 11. The error bars in the figure represent the standard deviation of repeated measurements at a given location.

From the information in Table 10 and Table 11, the range and $95 \%$ confidence levels $(2 \times$ standard deviation) were used to quantify the lattice spacing variability for each of the input boules and for the two 
boules together. The results are given in Table 12. The larger range for the WS4-SRM material is due to the measurement on crystal 2 (20 mm from center) discussed earlier.

Table 12. Calculation of the range and $95 \%$ confidence level for the SRM 640d input material.

\begin{tabular}{|c|c|c|c|}
\hline & WS3-SRM & WS4-SRM & $\begin{array}{c}\text { WS3-SRM \& WS4- } \\
\text { SRM }\end{array}$ \\
\hline Range & $47 \times 10^{-9}$ & $73 \times 10^{-9}$ & $79 \times 10^{-9}$ \\
\hline 95\% confidence level, 2 $\sigma$ & $\pm 26 \times 10^{-9}$ & $\pm 35 \times 10^{-9}$ & $\pm 33 \times 10^{-9}$ \\
\hline
\end{tabular}

A more useful estimate of the variability of the input material is provided by the standard deviation of the $\Delta d$ measurements given in Tables 10 and 11 . To a first approximation, each of the measurements in Tables 10 and 11 represents an equal volume of the input material, which would be ground and then mixed in the production of SRM 640d, 640e, and 640f. In the certification of SRMs, uncertainties are typically expressed as $95 \%$ confidence intervals $(2 \sigma)$. The values in Table 12 , row 3 , are the $95 \%$ confidence intervals ( $k=2$ expanded uncertainty) for each of the input boules and the two boules together. These lattice parameter distribution values confirm that the input material for SRMs 640d, 640e, and 640f has a uniform lattice spacing to a $k=2$ expanded uncertainty of $\Delta d / d \approx 30 \times 10^{-9}$.

Histograms of the measurement results represented in Tables 10 and 11 are shown in Fig. 9. The width of the histogram is consistent with the within-boule variability of $25 \times 10^{-9}$ that has been used previously in this paper.

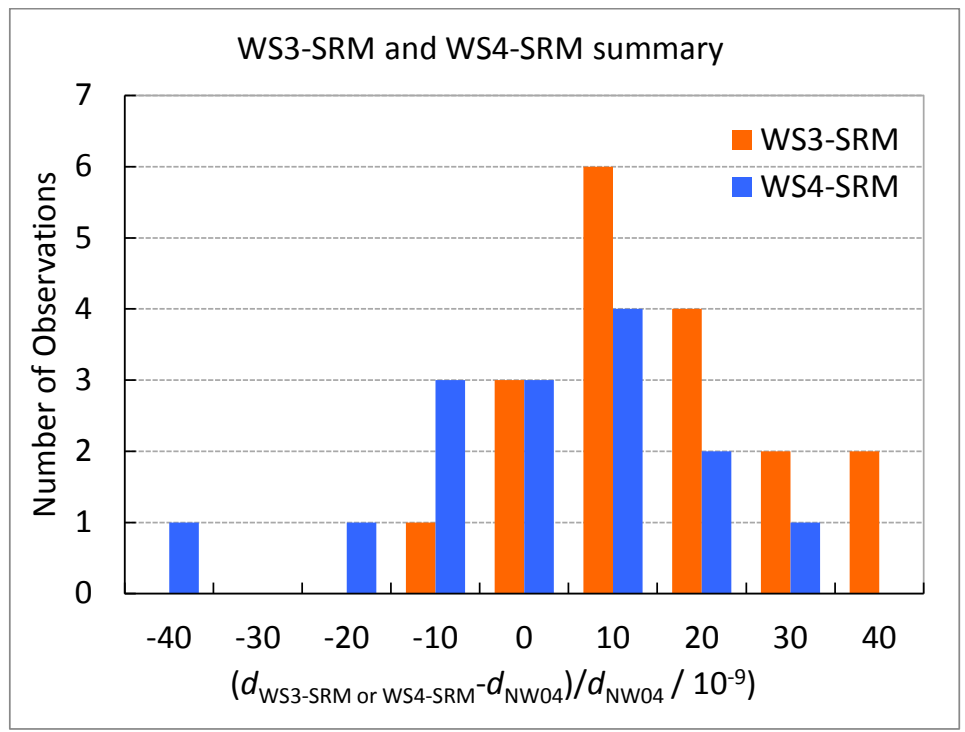

Fig. 9. Histograms of relative lattice spacing measurements for the WS3-SRM and WS4-SRM materials.

The lattice parameter values for the WS3-SRM and WS4-SRM silicon materials were determined by adjusting the absolute lattice spacing value of the NW04 standard sample by the measured lattice spacing differences between the WS3-SRM and WS4-SRM materials and the NW04 standard sample. Because the lattice spacings determined here will be associated with the entire boule, we chose the $95 \%$ confidence levels for the uncertainties of the lattice comparison. The lattice spacing differences and the absolute lattice spacing values are given in Table 13. 
Table 13. Calculation of the WS3-SRM and WS4-SRM $d_{220}$ values.

\begin{tabular}{|c|c|c|c|}
\hline $\begin{array}{c}\text { NW04 } d_{220} \\
t=22.5^{\circ} \mathrm{C}, p=0 \mathrm{~Pa}\end{array}$ & WS3-SRM & WS4-SRM & WS3-SRM \& WS4-SRM \\
\hline $\begin{array}{c}\left(d_{\mathrm{SRM}}-\right. \\
\left.d_{\mathrm{NW} 04}\right) / d_{\mathrm{NW} 04}\end{array}$ & $14(13) \times 10^{-9}$ & $2(17) \times 10^{-9}$ & $8(16) \times 10^{-9}$ \\
\hline $\begin{array}{c}\left(d_{\mathrm{SRM}}-\right. \\
\left.d_{\mathrm{NW} 04}\right) / d_{\mathrm{NW} 04} \\
\text { (expanded uncertainty })\end{array}$ & $14(26) \times 10^{-9}$ & $2(35) \times 10^{-9}$ & $8(33) \times 10^{-9}$ \\
\hline $\begin{array}{c}640 \mathrm{~d}, 640 \mathrm{e}, \text { and } \\
640 \mathrm{f} d_{220} \\
t=22.5^{\circ} \mathrm{C}, p=0 \mathrm{~Pa}\end{array}$ & $\begin{array}{c}192.0155723(51) \times 10^{-12} \\
\mathrm{~m}\end{array}$ & $\begin{array}{c}192.0155699(68) \times 10^{-12} \\
\mathrm{~m}\end{array}$ & $\begin{array}{c}192.0155712(64) \times 10^{-12} \\
\mathrm{~m}\end{array}$ \\
\hline
\end{tabular}

The difference between the $d_{220}$ values for WS3-PBD in Sec. 7 and for WS3-SRM in this section is much less than the uncertainties of the two measurements.

\subsection{Powder Diffraction SRM 640c}

The TS-SRM feedstock material was supplied by Topsil Semiconductor Materials, Denmark, as ten cylinders of vacuum float-zone silicon. Each cylinder had a diameter of $75 \mathrm{~mm}$ and a length as shown in Table 14a (along with the cylinder numbers given by the supplier). Disks, approximately $8 \mathrm{~mm}$ thick, were cut from each end of the ten cylinders (20 disks in all), and 20 crystal samples, $50 \mathrm{~mm}$ long, were produced (see Fig. 5).

The comparison of the 20 TS-SRM crystals to a standard took place during approximately five weeks in March and April 1997 before the W04 material was available to NIST. Thus, the crystals from the TSSRM silicon were compared to a sample of the W17 material supplied by PTB. A TS-SRM silicon sample and the W17 standard were aligned on the sample transport slide of the NIST lattice comparator. Each sample was measured in at least three places, which were usually at the center of the boule $(0 \mathrm{~mm}), 16 \mathrm{~mm}$ from the boule center, and $32 \mathrm{~mm}$ from the boule center. Both the standard and unknown crystals were carefully aligned at each measurement position.

The relative lattice spacing differences between the TS-SRM sample and the W17 standard $\left(d_{\text {TS-SRM }}-\right.$ $\left.d_{\mathrm{W} 17}\right) / d_{\mathrm{W} 17}$, are given in Table 14a. The R and L samples are from the right and left ends of each boule, respectively. Three additional measurements, which were made on two crystals (L21 and R37) at other radial locations (13 mm, $24 \mathrm{~mm}$, and $33 \mathrm{~mm}$ ), are reported in Table 14b. Each number is the average difference obtained from recording 16 to 24 profiles, and the uncertainty includes statistical and systematic contributions. Combining the 63 numbers in the tables, the average difference between the standard sample and the TS-SRM material is $\left(d_{\mathrm{TS}-\mathrm{SRM}}-d_{\mathrm{W} 17}\right) / d_{\mathrm{W} 17}=-23(23) \times 10^{-9}$. The uncertainty is the standard deviation of all 63 measurements. The $95 \%$ confidence interval $(2 \sigma)$ of these measurements is $47 \times 10^{-9}$ and is a reasonable measure of the variability of the TS-SRM silicon material that was used to produce SRM 640c. 
Table 14a. Lattice comparison results for the TS-SRM material.

\begin{tabular}{|c|c|c|c|c|c|}
\hline \multirow{3}{*}{$\begin{array}{l}\text { TS-SRM } \\
\text { Cylinder } \\
\text { Number }\end{array}$} & \multirow{3}{*}{$\begin{array}{l}\text { Length } \\
\text { (mm) }\end{array}$} & \multirow{3}{*}{ Crystal } & \multirow{2}{*}{\multicolumn{3}{|c|}{$\frac{\left(d_{\mathrm{TS}-S R M}-d_{\mathrm{W} 17}\right) / d_{\mathrm{W} 17}}{\text { Radial Location from Center }}$}} \\
\hline & & & & & \\
\hline & & & $0 \mathrm{~mm}$ & $16 \mathrm{~mm}$ & $32 \mathrm{~mm}$ \\
\hline \multirow{2}{*}{74270} & \multirow{2}{*}{216} & R70 & $-4(7) \times 10^{-9}$ & $-13(5) \times 10^{-9}$ & $5(6) \times 10^{-9}$ \\
\hline & & $\mathrm{L} 70$ & $-38(6) \times 10^{-9}$ & $-1(6) \times 10^{-9}$ & $-12(7) \times 10^{-9}$ \\
\hline \multirow{2}{*}{76151} & \multirow{2}{*}{323} & R51 & $-16(6) \times 10^{-9}$ & $-5(6) \times 10^{-9}$ & $-2(6) \times 10^{-9}$ \\
\hline & & L51 & $-51(7) \times 10^{-9}$ & $-16(8) \times 10^{-9}$ & $-34(10) \times 10^{-9}$ \\
\hline \multirow{2}{*}{76154} & \multirow{2}{*}{198} & R54 & $-59(6) \times 10^{-9}$ & $-20(7) \times 10^{-9}$ & $-22(6) \times 10^{-9}$ \\
\hline & & L54 & $-59(6) \times 10^{-9}$ & $-13(6) \times 10^{-9}$ & $-37(6) \times 10^{-9}$ \\
\hline \multirow{2}{*}{76172} & \multirow{2}{*}{210} & $\mathrm{R} 72$ & $-37(8) \times 10^{-9}$ & $-32(8) \times 10^{-9}$ & $-27(9) \times 10^{-9}$ \\
\hline & & $\mathrm{L} 72$ & $-49(7) \times 10^{-9}$ & $-30(6) \times 10^{-9}$ & $-58(7) \times 10^{-9}$ \\
\hline \multirow{2}{*}{76183} & \multirow{2}{*}{264} & R83 & $-23(6) \times 10^{-9}$ & $2(7) \times 10^{-9}$ & $-42(7) \times 10^{-9}$ \\
\hline & & L83 & $-43(7) \times 10^{-9}$ & $-19(6) \times 10^{-9}$ & $-46(9) \times 10^{-9}$ \\
\hline \multirow{2}{*}{76184} & \multirow{2}{*}{193} & R84 & $-37(9) \times 10^{-9}$ & $-49(6) \times 10^{-9}$ & $-30(7) \times 10^{-9}$ \\
\hline & & L84 & $-14(10) \times 10^{-9}$ & $4(7) \times 10^{-9}$ & $-82(7) \times 10^{-9}$ \\
\hline \multirow{2}{*}{76221} & \multirow{2}{*}{327} & R21 & $-40(7) \times 10^{-9}$ & $-11(7) \times 10^{-9}$ & $-16(7) \times 10^{-9}$ \\
\hline & & L21 & $-40(13) \times 10^{-9}$ & $7(9) \times 10^{-9}$ & $-37(7) \times 10^{-9}$ \\
\hline \multirow{2}{*}{76236} & \multirow{2}{*}{398} & R36 & $4(6) \times 10^{-9}$ & $-17(7) \times 10^{-9}$ & $-26(8) \times 10^{-9}$ \\
\hline & & L36 & $6(6) \times 10^{-9}$ & $31(10) \times 10^{-9}$ & $28(13) \times 10^{-9}$ \\
\hline \multirow{2}{*}{76237} & \multirow{2}{*}{308} & R37 & $-32(6) \times 10^{-9}$ & $-49(9) \times 10^{-9}$ & $-50(11) \times 10^{-9}$ \\
\hline & & L37 & $-62(5) \times 10^{-9}$ & $-28(14) \times 10^{-9}$ & $-16(19) \times 10^{-9}$ \\
\hline \multirow{2}{*}{76238} & \multirow{2}{*}{285} & R38 & $-6(6) \times 10^{-9}$ & $-6(8) \times 10^{-9}$ & $-33(11) \times 10^{-9}$ \\
\hline & & L38 & $3(8) \times 10^{-9}$ & $24(9) \times 10^{-9}$ & $14(11) \times 10^{-9}$ \\
\hline
\end{tabular}

Table 14b. Lattice comparison results for the TS-SRM silicon material at varied radial distances.

\begin{tabular}{|c|c|c|c|c|c|}
\hline \multirow{2}{*}{$\begin{array}{c}\text { TS-SRM } \\
\text { cylinder } \\
\text { number }\end{array}$} & \multirow{2}{*}{$\begin{array}{c}\text { Length } \\
(\mathrm{mm})\end{array}$} & Crystal & \multicolumn{3}{|c|}{$\left(d_{\mathrm{TS}-\mathrm{SRM}}-d_{\mathrm{W} 17}\right) / d_{\mathrm{W} 17}$} \\
\cline { 4 - 6 } & & & \multicolumn{3}{|c|}{ Radial Location from Center } \\
\cline { 4 - 6 } & & & $13 \mathrm{~mm}$ & $24 \mathrm{~mm}$ & $33 \mathrm{~mm}$ \\
\hline 76221 & 327 & L21 & & $-47(5) \times 10^{-9}$ & \\
\hline 76237 & 308 & R37 & $-16(8) \times 10^{-9}$ & & $-26(9) \times 10^{-9}$ \\
\hline
\end{tabular}

A histogram showing the number of lattice difference measurements in a particular $10 \times 10^{-9}$ range is shown in Fig. 10. This figure provides a picture of the uniformity of the TS-SRM material and the lattice spacing difference and uncertainty between the W17 standard and the TS-SRM silicon. 


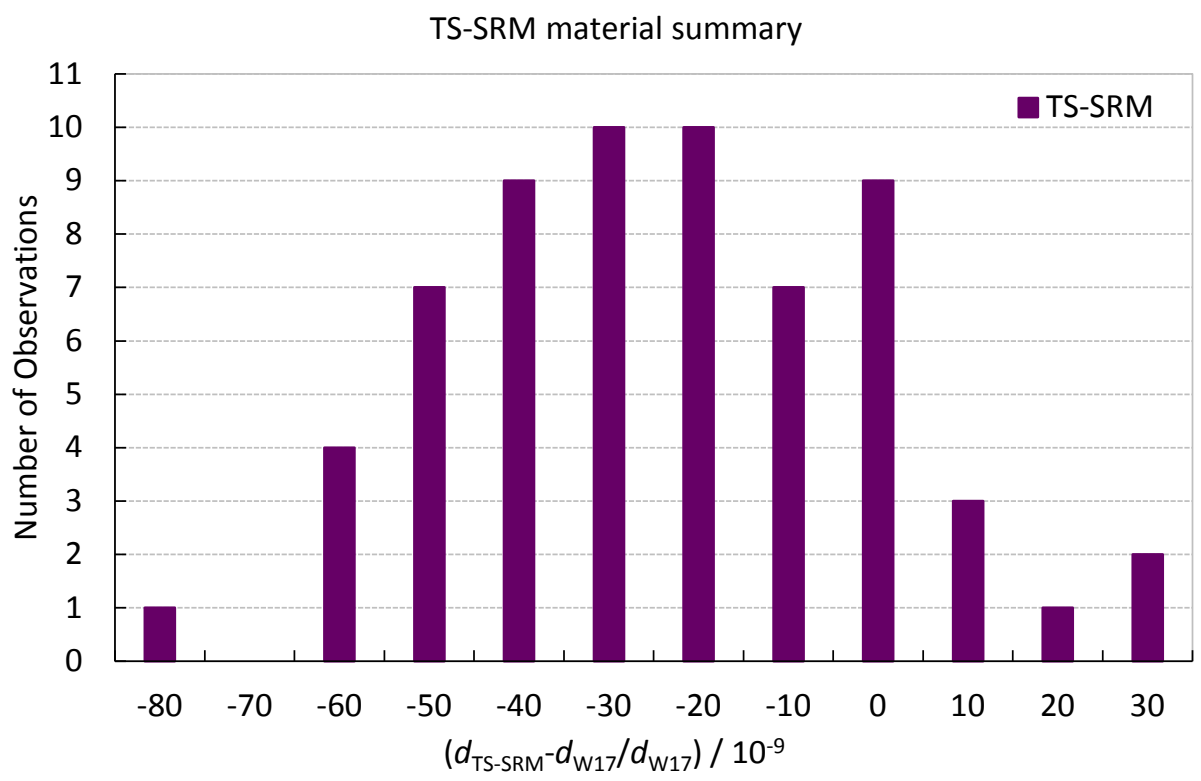

Fig. 10. Histogram of all 63 relative lattice spacing measurements performed for the TS-SRM material.

The lattice parameter value for the TS-SRM silicon was determined by combining (1) the absolute lattice parameter value of the NW04 crystal given above, (2) the lattice parameter difference between W17 and NW04 from Ref. [3], and (3) the lattice parameter difference between the TS-SRM silicon and the W17 standard reported here. The lattice parameter value for the TS-SRM silicon is given in Table 15, along with the values associated with the three input measurements. The $95 \%$ confidence interval was used for the relative uncertainty of the TS-SRM to W17 comparison because the lattice parameter value is associated with the entire lot of TS-SRM material.

Table 15. Calculation of the TS-SRM $d_{220}$ value.

\begin{tabular}{|c|c|}
\hline NW04 $d_{220} t=22.5^{\circ} \mathrm{C}, p=0$ Pa & $192.0155696(10) \times 10^{-12} \mathrm{~m}$ \\
\hline$\left(d_{\mathrm{TS}-\mathrm{SRM}}-d_{\mathrm{W} 17}\right) / d_{\mathrm{W} 17}($ expanded uncertainty $)$ & $-23(47) \times 10^{-9}$ \\
\hline$\left(d_{\mathrm{W} 17}-d_{\mathrm{NW} 04}\right) / d_{\mathrm{NW} 04}$ & $11(5) \times 10^{-9}$ \\
\hline$\left(d_{\mathrm{TS}-\mathrm{SRM}}-d_{\mathrm{NW} 04}\right) / d_{\mathrm{N} \text { } 04}($ expanded uncertainty) & $-12(47) \times 10^{-9}$ \\
\hline $\mathrm{TS}-\mathrm{SRM} d_{220} t=22.5^{\circ} \mathrm{C}, p=0 \mathrm{~Pa}$ & $192.0155673(90) \times 10^{-12} \mathrm{~m}$ \\
\hline
\end{tabular}

\section{Summary}

In this paper, the most accurate X-ray/optical interferometer lattice spacing measurements on a nearly perfect float-zone Si material, W04, were transferred to six unknown Si samples by lattice comparison measurements. The lattice comparison results include measurements made at NIST over the past 20 years. Some of the measurements have been previously published, some have appeared in internal reports and calibration certificates, and some are recent measurements and internal consistency checks. The recent measurements were made to provide a more direct connection between the W04 material and the samples used in standards programs at NIST. The lattice spacing of unknown Si samples determined in this paper are collected in Table 16 and Fig. 11. 
Table 16. Summary of the lattice spacings determined in this manuscript.

\begin{tabular}{|l|l|l|l|}
\hline $\begin{array}{l}\text { Si Material } \\
\text { Name }\end{array}$ & $\begin{array}{l}\text { Year of NIST } \\
\text { Lattice } \\
\text { Comparison }\end{array}$ & $\begin{array}{l}\text { Diffraction Instruments Using } \\
\text { this Si Material }\end{array}$ & $d_{220}\left(t=22.5^{\circ} \mathrm{C}, p=0 \mathrm{~Pa}\right)$ \\
\hline WS1 & 2016 & NIST VDCS \& GAMS4 & $192.0155658(52) \times 10^{-12} \mathrm{~m}$ \\
\hline ILL & 2001 & GAMS4 & $192.0155721(64) \times 10^{-12} \mathrm{~m}$ \\
\hline WS2 & 2004 & LKB VDCS & $192.0155651(50) \times 10^{-12} \mathrm{~m}$ \\
\hline WS3-PBD & 2013 & NIST PBD & $192.0155712(52) \times 10^{-12} \mathrm{~m}$ \\
\hline WS3-SRM & 2006 & SRM 640d, 640e, 640f & $192.0155723(51) \times 10^{-12} \mathrm{~m}$ \\
\hline WS4-SRM & 2006 & SRM 640d, 640e, 640f & $192.0155699(68) \times 10^{-12} \mathrm{~m}$ \\
\hline TS-SRM & 1997 & SRM 640c & $192.0155673(90) \times 10^{-12} \mathrm{~m}$ \\
\hline
\end{tabular}

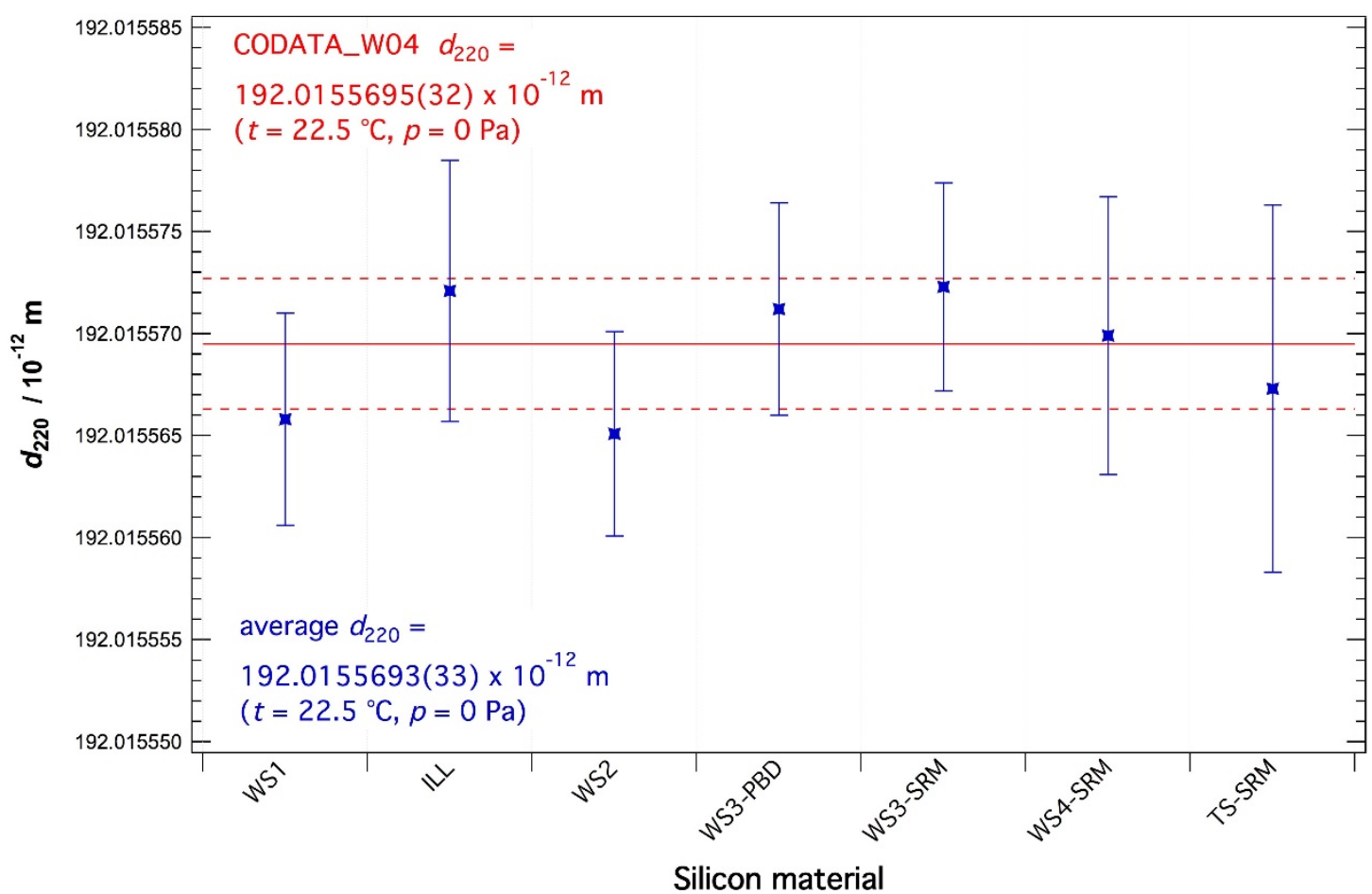

Fig. 11. Comparison of lattice spacings (blue markers with error bars) determined via lattice comparison measurements described in this paper. The solid red line represents the 2014 CODATA recommendation corrected to include impurities, with its uncertainty given as dashed lines.

All the measurements in this report involved high-quality natural silicon material grown under wellcontrolled conditions. Four of the samples were supplied by one company (Wacker-Siltronic), but over a 20 year span. The SRM materials (WS3-SRM, WS4-SRM, and TS-SRM) involved many lattice comparisons, which were averaged to get the values and uncertainties in Table 16. The seven lattice spacings in Table 16 have a small spread, indicating the reliability of commercial silicon crystal growth techniques for the materials included in this study. The maximum and minimum values (the range) have a relative difference of $3.8 \times 10^{-8}$. The average value (and uncertainty at one standard deviation) is $d_{220 \text {, ave }}=192.015569$ $1(30) \times 10^{-12} \mathrm{~m}$ at $t=22.5^{\circ} \mathrm{C}, p=0 \mathrm{~Pa}$ (relative standard uncertainty $1.6 \times 10^{-8}$ ).

The 2014 CODATA recommended value for the $\mathrm{Si}(220)$ lattice spacing at $22.5^{\circ} \mathrm{C}$ in vacuum is $d_{220}=192.0155714(32) \times 10^{-12} \mathrm{~m}$ [15]. This value is for an ideal single crystal of naturally occurring $\mathrm{Si}$ that is free of impurities and imperfections and was obtained through the adjustment process using a collection of X-ray/optical interferometry measurements and lattice spacing comparisons and includes corrections for impurities carefully measured within the W04 material [29]. In the collection of input data, the X-ray/optical interferometry measurement for the W04 material contributed the smallest uncertainty 
and thus carried the largest weighting. For the W04 boule, the presence of carbon, oxygen, and nitrogen impurities introduced a relative reduction of the lattice spacing from the idealized CODATA value by $\Delta d_{\text {imp }} / d=-10(5) \times 10^{-9}[29]$. Applying this correction to the 2014 CODATA value produces:

CODATA_W04 $d_{220}=192.0155695(33) \times 10^{-12}\left(t=22.5^{\circ} \mathrm{C}, p=0 \mathrm{~Pa}, \Delta d_{\text {imp }} / d\right.$ applied $)$, which is very close to the values assigned to the lattice comparator standard crystal (NW04), and which is essentially indistinguishable from the average of the Si materials that were measured in this study and plotted in Fig. 11. Hence, when working with high-quality nearly perfect float-zone Si single crystals, it is reasonable to employ this 2014 CODATA recommended value, corrected for typical impurity levels and indicated in red in Fig. 11. For more demanding applications, lattice comparison facilities exist to verify the lattice spacing of particular and special samples.

For most diffraction instruments, the uncertainty in the wavelength scale is limited by the diffraction angle measurement and not the crystal lattice spacing values. The lattice spacing values and uncertainties in Table 16 are likely, for the foreseeable future, to be useful for the ongoing development and dissemination of NIST wavelength and powder diffraction X-ray standards that rely upon the crystal diffraction method.

\section{Acknowledgments}

Author C.I. Szabo performed this work with financial assistance under award no. 70NANB15H051 from U.S. Department of Commerce, National Institute of Standards and Technology.

\section{References}

[1] Kessler EG, Henins A, Deslattes RD, Nielsen L, Arif M (1994) Precision comparison of the lattice parameters of silicon monocrystals. Journal of research of the National Institute of Standards and Technology 99(1):1-18. https://doi.org/10.6028/jres.099.002

[2] Kessler EG, Owens SM, Henins A, Deslattes RD (1999) Silicon lattice comparisons related to the Avogadro project: Uniformity of new material and surface preparation effects. IEEE Transactions on Instrumentation and Measurement 48(2):221-224. http://doi.org/10.1109/19.769568

[3] Hanke M, Kessler EG (2005) Precise lattice parameter comparison of highly perfect silicon crystals. Journal of Physics D: Applied Physics 38(10A):A117-A120. https://doi.org/10.1088/0022-3727/38/10A/022

[4] Massa E, Mana G, Ferroglio L, Kessler EG, Schiel D, Zakel S (2011) The lattice parameter of the ${ }^{28}$ Si spheres in the determination of the Avogadro constant. Metrologia 48(2):S44-S49. https://doi.org/10.1088/0026-1394/48/2/s07

[5] Vaudin MD, Kessler EG, Owen DM (2011) Precise silicon die curvature measurements using the NIST lattice comparator: comparisons with coherent gradient sensing interferometry. Metrologia 48(3):201-211. http://dx.doi.org/10.1088/00261394/48/3/015

[6] Deslattes RD (1967) Two-Crystal, Vacuum Monochromator. Rev. Sci. Instrum. 38(5):616-620. http://doi.org/10.1063/1.1720781

[7] Mendenhall MH, Henins A, Windover D, Cline JP (2016) Characterization of a self-calibrating, high-precision, stacked-stage, vertical dual-axis goniometer. Metrologia 53(3):933-944. http://doi.org/10.1088/0026-1394/53/3/933

[8] Kessler EG, Dewey MS, Deslattes RD, Henins A, Borner HG, Jentschel M, Lehmann H (2001) The GAMS4 flat crystal facility. Nucl Instrum Meth A 457(1-2):187-202. https://doi.org/10.1016/S0168-9002(00)00753-1

[9] Amaro P, Szabo CI, Schlesser S, Gumberidze A, Kessler Jr EG, Henins A, Le Bigot EO, Trassinelli M, Isac JM, Travers P, Guerra M, Santos JP, Indelicato P (2014) A vacuum double-crystal spectrometer for reference-free X-ray spectroscopy of highly charged ions. Radiation Physics and Chemistry 98(0):132-149. http://dx.doi.org/10.1016/j.radphyschem.2014.01.015

[10] Black DR, Windover D, Henins A, Gil D, Filliben J, Cline JP (2010) Certification of NIST Standard Reference Material 640d. Powder Diffr 25(2):187-190. https://doi.org/10.1154/1.3409482

[11] NIST (2000) Standard Reference Material 640c: Silicon Powder Line position and line shape standard for powder diffraction. (NIST, U.S. Department of Commerce, Gaithersburg, MD, USA, 13 September 2000, URL: https://wwws.nist.gov/srmors/view_detail.cfm?srm=640C).

[12] NIST (2009) Standard Reference Material 640d: Silicon Powder Line position and line shape standard for powder diffraction. SRM certificate. (NIST, U.S. Department of Commerce, Gaithersburg, MD, USA, 09 July 2009, URL: https://wwws.nist.gov/srmors/view_detail.cfm?srm=640D).

[13] NIST (2015) Standard Reference Material 640e: Line Position and Line Shape Standard for Powder Diffraction (silicon powder). (NIST, U.S. Department of Commerce, Gaithersburg, MD, USA, 10 March 2015, URL: https://wwws.nist.gov/srmors/view_detail.cfm?srm=640E).

[14] NIST (2018) Standard Reference Material 640f: Line Position and Line Shape Standard for Powder Diffraction (silicon powder). (NIST, U.S. Department of Commerce, Gaithersburg, MD, USA, to be certified in 2018).

[15] Mohr PJ, Newell DB, Taylor BN (2016) CODATA recommended values of the fundamental physical constants: 2014. Rev. Mod. Phys. 88(3):035009. https://doi.org/10.1103/RevModPhys.88.035009

[16] Ando M, Bailey D, Hart M (1978) A simple Bragg-spacing comparator. Acta Crystallographica Section A 34(4):484-489. https://doi.org/10.1107/S0567739478001047 
[17] Fujimoto H, Waseda A, Zhang XW (2011) Homogeneity characterization of lattice spacing of silicon single crystals by a selfreferenced lattice comparator. Metrologia 48(2):S55-S61. https://doi.org/10.1088/0026-1394/48/2/s09

[18] Hart M (1969) High Precision Lattice Parameter Measurements by Multiple Bragg Reflexion Diffractometry. Proceedings of the Royal Society of London A: Mathematical, Physical and Engineering Sciences 309(1497):281-296. http://doi.org/10.1098/rspa.1969.0042

[19] Deslattes RD, Henins A (1973) X-Ray to Visible Wavelength Ratios. Phys. Rev. Lett. 31(16):972-975. https://doi.org/10.1103/PhysRevLett.31.972

[20] Deslattes RD, Henins A, Schoonover RM, Carroll CL, Bowman HA (1976) Avogadro Constant - Corrections to an Earlier Report. Phys. Rev. Lett. 36(15):898-900. https://doi.org/10.1103/PhysRevLett.36.898

[21] Becker P, Dorenwendt K, Ebeling G, Lauer R, Lucas W, Probst R, Rademacher H-J, Reim G, Seyfried P, Siegert H (1981) Absolute Measurement of the (220) Lattice Plane Spacing in a Silicon Crystal. Phys. Rev. Lett. 46(23):1540-1543. http://doi.org/10.1103/PhysRevLett.46.1540

[22] Windisch D, Becker P (1990) Silicon lattice parameters as an absolute scale of length for high precision measurements of fundamental constants. Physica status solidi. A, Applied research 118(2):379-388. https://doi.org/10.1002/pssa.2211180205

[23] Basile G, Bergamin A, Cavagnero G, Mana G, Vittone E, Zosi G (1994) Measurement of the Silicon (220) Lattice Spacing. Phys. Rev. Lett. 72(20):3133-3136. https://doi.org/10.1103/PhysRevLett.72.3133

[24] Nakayama K, Fujimoto H (1997) Progress in the measurement of lattice spacing d(220) of silicon. IEEE Transactions on Instrumentation and Measurement 46(2):580-583. https://doi.org/10.1109/19.571922

[25] Becker P, Cavagnero G, Kuetgens U, Mana G, Massa E (2007) Confirmation of the INRiM and PTB Determinations of the Si Lattice Parameter. IEEE Transactions on Instrumentation and Measurement 56(2):230-234. https://doi.org/10.1109/TIM.2007.890618

[26] Massa E, Mana G, Kuetgens U (2009) Comparison of the INRIM and PTB lattice-spacing standards. Metrologia 46(3):249.

[27] Cavagnero G, Fujimoto H, Mana G, Massa E, Nakayama K, Zosi G (2004) Measurement repetitions of the Si(220) lattice spacing. Metrologia 41(1):56-64. http://dx.doi.org/10.1088/0026-1394/41/1/008

[28] Cavagnero G, Fujimoto H, Mana G, Massa E, Nakayama K, Zosi G (2004) Measurement repetitions of the Si(220) lattice spacing (Erratum). Metrologia 41(6):445-446. http://dx.doi.org/10.1088/0026-1394/41/6/C01

[29] Becker P, Bettin H, Danzebrink HU, Gläser M, Kuetgens U, Nicolaus A, Schiel D, Bièvre PD, Valkiers S, Taylor P (2003) Determination of the Avogadro constant via the silicon route. Metrologia 40(5):271-287. https://doi.org/10.1088/0026$1394 / 40 / 5 / 010$

[30] Martin J, Kuetgens U, Stümpel J, Becker P (1998) The silicon lattice parameter - an invariant quantity of nature? Metrologia 35(6):811-817. http://dx.doi.org/10.1088/0026-1394/35/6/4

[31] Fujii K, Waseda A, Kuramoto N, Mizushima S, Becker P, Bettin H, Nicolaus A, Kuetgens U, Valkiers S, Taylor P, Paul DB, Mana G, Massa E, Matyi R, Kessler EG, Jr., Hanke M (2005) Present State of the avogadro constant determination from silicon Crystals with natural isotopic compositions. IEEE Transactions on Instrumentation and Measurement 54(2): 854-859. https://doi.org/10.1109/TIM.2004.843101

[32] Massa E, Mana G, Kuetgens U, Ferroglio L (2009) Measurement of the lattice parameter of a silicon crystal. New Journal of Physics 11(5):053013. https://doi.org/10.1088/1367-2630/11/5/053013

[33] Massa E, Mana G, Kuetgens U, Ferroglio L (2010) Calibration of a silicon crystal for absolute nuclear spectroscopy. Journal of Applied Crystallography 43(2):293-296. https://doi.org/10.1107/S0021889810001652

[34] Schoedel R, Boensch G (2001) Precise interferometric measurements at single-crystal silicon yielding thermal expansion coefficients from $12^{\circ}$ to $28^{\circ} \mathrm{C}$ and compressibility. Recent Developments in Traceable Dimensional Measurements, (SPIE), pp 54-62. http://doi.org/10.1117/12.445624

[35] McSkimin HJ, Andreatch P (1964) Elastic Moduli of Silicon vs Hydrostatic Pressure at $25.0^{\circ} \mathrm{C}$ and $-195.8^{\circ} \mathrm{C}$. Journal of Applied Physics 35(7):2161-2165. https://doi.org/10.1063/1.1702809

[36] Mooney T, Lindroth E, Indelicato P, Kessler E, Deslattes RD (1992) Precision measurements of K and L transitions in xenon: Experiment and Theory for the K, L and M levels. Phys. Rev. A 45(3):1531-1543. https://doi.org/10.1103/PhysRevA.45.1531

[37] Schweppe J, Deslattes RD, Mooney T, Powell CJ (1994) Accurate measurement of Mg and Al Ka 1,2 X-ray energy profiles. Journal of Electron Spectroscopy and Related Phenomena 67(3):463-478. https://doi.org/10.1016/0368-2048(93)02059-U

[38] Kessler EG, Dewey MS, Deslattes RD, Henins A, Borner HG, Jentschel M, Doll C, Lehmann H (1999) The deuteron binding energy and the neutron mass. Physics Letters A 255(4-6):221-229. http://doi.org/10.1016/S0375-9601(99)00078-X

[39] Dewey MS, Kessler EG, Deslattes RD, Borner HG, Jentschel M, Doll C, Mutti P (2006) Precision measurement of the Si-29, S33, and Cl-36 binding energies. Phys. Rev. C 73(4):044303. https://doi.org/10.1103/Physrevc.73.044303

[40] Mohr PJ, Taylor BN (2000) CODATA recommended values of the fundamental physical constants: 1998. Rev. Mod. Phys. 72(2):351-495. https://doi.org/10.1103/RevModPhys.72.351

[41] Amaro P, Schlesser S, Guerra M, Le Bigot EO, Isac JM, Travers P, Santos JP, Szabo CI, Gumberidze A, Indelicato P (2012) Absolute Measurement of the Relativistic Magnetic Dipole Transition Energy in Heliumlike Argon. Phys. Rev. Lett. 109(4):043005. https://doi.org/10.1103/PhysRevLett.109.043005

[42] Gumberidze A, Trassinelli M, Adrouche N, Szabo CI, Indelicato P, Haranger F, Isac J-M, Lamour E, Bigot E-OL, Merot J, Prigent C, Rozet J-P, Vernhet D (2010) Electronic temperatures, densities, and plasma x-ray emission of a $14.5 \mathrm{GHz}$ electroncyclotron resonance ion source. Rev. Sci. Instrum. 81(3):033303. http://dx.doi.org/10.1063/1.3316805

[43] Szabo CI, Amaro P, Guerra M, Santos JP, Gumberidze A, Attard J, Indelicato P (2013) Ion temperature and x-ray line width measurements of highly charged argon ions in an ECR ion source. Physica Scripta T156:014077. http://dx.doi.org/10.1088/0031-8949/2013/t156/014077

[44] Kinnane MN, Hudson LT, Henins A, Mendenhall MH (2015) A simple method for high-precision calibration of long-range errors in an angle encoder using an electronic nulling autocollimator. Metrologia 52(2):244-250. http://dx.doi.org/10.1088/0026$1394 / 52 / 2 / 244$ 
[45] Mendenhall MH, Windover D, Henins A, Cline JP (2015) An algorithm for the compensation of short-period errors in optical encoders. Metrologia 52(5):685-693. http://doi.org/10.1088/0026-1394/52/5/685

[46] Mendenhall MH, Henins A, Hudson LT, Szabo CI, Windover D, Cline JP (2017) High-precision measurement of the X-ray Cu Ka spectrum. Journal of Physics B. https://doi.org/10.1088/1361-6455/aa6c4a

[47] van Berkum JGM, Sprong GJM, de Keijser TH, Delhez R, Sonneveld EJ (1995) The optimum standard specimen for X-ray diffraction line-profile analysis. Powder Diffraction Journal 10(02):129-139. http://doi.org/10.1017/S0885715600014512

[48] Smith FW, Ghidini G (1982) Reaction of Oxygen with Si(111) and (100): Critical Conditions for the Growth of SiO2. J. Electrochem. Soc. 129(6):1300-1306. https://doi.org/10.1149/1.2124122

[49] Cline JP, Mendenhall MH, Black D, Windover D, Henins A (2015) The Optics and Alignment of the Divergent Beam Laboratory X-ray Powder Diffractometer and its Calibration Using NIST Standard Reference Materials. Journal of Research of the National Institute of Standards and Technology 120:173-222. https://doi.org/10.6028/jres.120.013

[50] EerNisse EP (1979) Stress in thermal SiO2 during growth. Applied Physics Letters 35(1):8-10. https://doi.org/10.1063/1.90905

About the authors: Ernest G. Kessler retired from the Atomic Physics Division in 2003 and currently is a contracting scientist in the Materials Measurement Science Division at NIST. Ernest G. Kessler worked at NIST for 47 years and spent most of his carrier performing precision X-ray measurements.

Csilla I. Szabo is a NIST grant holder in the Radiation Physics Division at NIST. Csilla I. Szabo is dedicated to continuing the world-renowned X-ray metrology at NIST, and she is currently working on precision measurements of $X$-ray transition energies to validate and improve standard reference data in the field.

James P. Cline is a staff scientist in the Materials Measurement Science Division at NIST. James P. Cline's primary contribution includes the suite of NIST SRMs by which the worldwide X-ray wavelength diffraction community calibrates its equipment and measurements.

Albert Henins retired from the Atomic Physics Division in 1999 and currently is a contracting scientist in the Materials Measurement Science Division at NIST. Albert Henins worked at NIST for 46 years, during which he was involved in various $X$-ray metrology projects, including the connection of the absolute (SI) scale to a silicon crystal lattice.

Lawrence T. Hudson is a staff scientist in the Radiation Physics Division at NIST. Larry Hudson's research interests include precision X-ray metrology, curved crystal spectrometry, and the development of national and international standards related to security-screening applications of ionizing radiation.

Marcus Mendenhall joined the NIST staff in 2014, after 30 years on the faculty at Vanderbilt University. He has worked primarily on ionizing radiation effects in materials and computational techniques for data analysis and modeling. He is working at NIST on high-precision X-ray diffraction measurements in powders, and high-precision X-ray line shape measurements.

Mark D. Vaudin is a staff scientist in the Materials Measurement Science Division at NIST. Mark D. Vaudin has been working on various $X$-ray diffraction projects, including high resolution $X$-ray diffraction using a lattice comparator with $10^{-8}$ accuracy for lattice spacing and strain standards development.

The National Institute of Standards and Technology is an agency of the U.S. Department of Commerce. 